\title{
Consenso mexicano de linfoma de Hodgkin
}

José L. Álvarez-Vera', Jocelyn Aguilar-Luevano², Luisa M. Alcívar-Cedeño', Luara L. Arana-Luna1, Luis Arteaga-Ortiz³, Pamela E. Báez-Islas ${ }^{4}$, Ana Carolina-Reynoso ${ }^{1}$, Gabriela Cesarman-Maus ${ }^{5}$, José A. De la Peña-Celaya ${ }^{1}$, María E. Espitia-Ríos ${ }^{1}$, Denisse J. Fermín-Caminero', Willy Flores-Patricio ${ }^{6}$, Alinka S. García-Camacho ${ }^{7}$, Pedro G. Guzmán-Mora1, Ana K. Hernández-Colín', Eleazar Hernández-Ruiz', Wilfrido Herrera-Olivares ${ }^{8}$, Elvia Jacobo-Medrano ${ }^{9}$, Sergio J. Loera-Fragoso ${ }^{10}$, Juan P. Macías-Flores' ${ }^{1}$ Mario A. Martínez-Ramírez ${ }^{11}$, Liliana Medina-Guzmán ${ }^{12}$, Andrea I. Milán-Salvatierra ${ }^{5}$, Leire Montoya-Jiménez', Javier de J. Morales-Adrián ${ }^{13}$, Aldo Mujica-Martínez ${ }^{14}$, Lorena Nava-Villegas', Juan J. Orellana-Garibay ${ }^{6}$, Orlando G. Palma-Moreno', Juan M. Pérez-Zúñiga', Karen D. Pérez-Gómez', Yayra M. Pichardo-Cepín ${ }^{1}$, Flavio Rojas-Castillejos', Eduardo Romero-Martínez ${ }^{15}$, Hilda Romero-Rodelo ${ }^{16}$, Adela Segura-García1, Karina Silva-Vera ${ }^{17}$, Ana L. Tapía-Enríquez ${ }^{18}$, Óscar Teomitzi-Sánchez', Fredy Tepepa-Flores ${ }^{1}$, Shendel P. Vilchis-González', Atenas Villela-Peña ${ }^{1}$, Lidia V. Guerra-Alarcón ${ }^{19}$, Rodrigo Reséndiz-Olea ${ }^{20}$, Luisa Banda-García ${ }^{21}$, Eugenia P. Paredes-Lozano ${ }^{22}$ y Martha Alvarado-Ibarra ${ }^{1 *}$

${ }^{1}$ Servicio de Hematología, Centro Médico Nacional 20 de noviembre, Instituto de Seguridad y Servicios Sociales de los Trabajadores del Estado (ISSSTE), Ciudad de México; ${ }^{2}$ Servicio de Hematología, Hospital General Regional 2 El Marqués, Instituto Mexicano del Seguro Social (IMSS), Santiago de Querétaro, Qro.; 'Servicio de Hematología, Hospital General "Dr. Carlos Estrada Ruibal", Instituto de Seguridad y Servicios Sociales de los Trabajadores del Estado (ISSSTE), La Paz, B.C.S.; ${ }^{4}$ Servicio de Hematología, Hospital Ángeles Lomas, Ciudad de México; ${ }^{5}$ Servicio de Hematología, Instituto Nacional de Cancerología, Ciudad de México; ${ }^{6}$ Servicio de Hematología, Hospital General, Instituto de Seguridad y Servicios

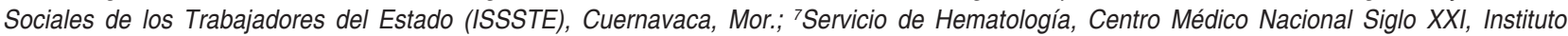
Mexicano del Seguro Social (IMSS), Ciudad de México; ${ }^{8}$ Servicio de Hematología, Hospital Regional, Instituto de Seguridad y Servicios Sociales de los Trabajadores del Estado (ISSSTE), Puebla, Pue.; ${ }^{9}$ Servicio de Hematología, Hospital General, Instituto de Seguridad y Servicios Sociales de los Trabajadores del Estado (ISSSTE), Aguascalientes, Ags.; ${ }^{10}$ Servicio de Hematología, Hospital Regional Santiago Ramón y Cajal, Instituto de Seguridad y Servicios Sociales de los Trabajadores del Estado (ISSSTE), Durango, Dgo.; ${ }^{11}$ Servicio de Hematología, Hospital Alta Especialidad Veracruz, Ver.; ${ }^{12}$ Servicio de Hematología, Hospital General, Instituto de Seguridad y Servicios Sociales de los Trabajadores del Estado (ISSSTE), Querétaro, Qro.; ${ }^{13}$ Servicio de Hematología, Hospital Regional, Instituto de Seguridad y Servicios Sociales de los Trabajadores del Estado (ISSSTE), Mérida, Yuc.; ${ }^{14}$ Servicio de Hematología, Hospital Ángeles Clínica Londres, Ciudad de México; ${ }^{15}$ Servicio de Hematología, Hospital General, Instituto de Seguridad y Servicios Sociales de los Trabajadores del Estado (ISSSTE), Mexicali, B.C.; ${ }^{16}$ Servicio de Hematología, Hospital General, Instituto de Seguridad y Servicios Sociales de los Trabajadores del Estado (ISSSTE), Tijuana, B.C.; ${ }^{17}$ Servicio de Hematología, Hospital General, Instituto de Seguridad y Servicios Sociales de los Trabajadores del Estado (ISSSTE), Tampico, Tamps.; ${ }^{18}$ Servicio de Hematología, Hospital General Presidente Lázaro Cárdenas, Instituto de Seguridad y Servicios Sociales de los Trabajadores del Estado (ISSSTE), Chihuahua, Chih.; ${ }^{19}$ Servicio de Hematología, Centro Regional de Hemato-Oncología , Grupo CREHO, Guatemala; ${ }^{20}$ Servicio de Hematología, Hospital Regional Zaragoza,Ciudad de México, México; ${ }^{21}$ Servicio de Hematología, Hospital General de Zona 11, Instituto Mexicano del Seguro Social (IMSS), Xalapa Ver.; ${ }^{22}$ Servicio de Hematología, Hospital Regional 1 de Octubre, Instituto de Seguridad y Servicios Sociales de los Trabajadores del Estado (ISSSTE), Ciudad de México. México

\section{Resumen}

El linfoma de Hodgkin $(\mathrm{LH})$ se debe a la transformación clonal de células originadas en los linfocitos $B$, lo que genera las células binucleadas patognomónicas de Reed-Sternberg. El LH es una enfermedad de células B con una distribución bimodal, con mayor incidencia en la adolescencia y la tercera década de la vida y un segundo pico en personas mayores de 55 años. Las células del LH clásico habitualmente sufren una reprogramación de la expresión génica, ya que pierden la expresión de

Correspondencia:

*Martha Alvarado-Ibarra

E-mail: normoblasto@gmail.com
Fecha de recepción: 27-10-2020

Fecha de aceptación: 05-01-2021

DOI: $10.24875 / G M M . M 21000500$
Gac Med Mex. 2021;157(Supl 2):S1-S18

Disponible en PubMed

www.gacetamedicademexico.com CC BY-NC-ND (http://creativecommons.org/licenses/by-nc-nd/4.0/). 
la mayoría de los genes típicos de las células $B$ y han adquirido la expresión de múltiples genes que son típicos de otros tipos de células del sistema inmunitario. El algoritmo de tratamiento dependerá si se trata de LH clásico o de predominio linfocítico, si es un estadio temprano con marcadores de pronóstico desfavorables o no, el esquema inicial de manejo y si existe enfermedad voluminosa, entre las variables más relevantes.

PALABRAS CLAVE: Reed-Sternberg. Inmunohistoquímica. Brentuximab. Quimioterapia. Deauville.

\title{
Mexican Consensus on Hodgkin's Lymphoma
}

\begin{abstract}
Hodgkin's lymphoma is due to the clonal transformation of cells originating from B lymphocytes, generating the pathognomonic binucleate Reed-Sternberg cells. Hodgkin's lymphoma is a B cell disease with a bimodal distribution, with higher incidence in adolescence and the third decade of life, showing a second peak in people over 55 years of age. Classic Hodgkin lymphoma cells routinely undergo gene expression reprogramming, as they lose the expression of most of the typical B-cell genes and acquire the expression of multiple genes that are typical of other types of cells in the immune system. The treatment algorithm will depend on whether it is classic or predominantly lymphocytic $\mathrm{HL}$, if it is early stage with unfavorable prognostic markers or not, the initial management regimen, and whether there is bulky disease, among the most relevant variables.
\end{abstract}

KEY WORD: Reed sternberg. Inmunohistochemical. Brentuximab. Quimioterapy. Deauville.

\section{Introducción}

El linfoma de Hodgkin (LH), también denominado enfermedad de Hodgkin, es una neoplasia del sistema linfático.

El sistema linfático está formado por finos conductos que se ramifican por todo el cuerpo. Su función consiste en combatir las infecciones y las enfermedades neoplásicas. El sistema linfático transporta un líquido incoloro denominado linfa, que contiene linfocitos ( $B$ y $T$ ). Los linfocitos $B$ (también llamados células B) generan anticuerpos para combatir infecciones y los linfocitos $T$ (células $T$ ) destruyen virus y células extrañas y activan a las células $B$ para que generen anticuerpos. Los ganglios linfáticos se encuentran en grupos, en el abdomen, la ingle, la pelvis, las axilas, el tórax y el cuello. En los ganglios linfáticos se produce la maduración y activación de los linfocitos para que desarrollen su función fisiológica.

El sistema linfático también incluye el bazo (que produce linfocitos y filtra la sangre), el timo (que es un órgano ubicado debajo del esternón) y las amígdalas (que se encuentran en la garganta).

El LH se forma a partir de un linfocito $B$ que se encuentra en proceso de maduración/activación en el ganglio linfático. Este linfocito sufre una alteración en los genes que regulan su capacidad para producir anticuerpos y se convierte en una célula incapaz de llevar a cabo su función fisiológica y, por tanto, debe morir en el ganglio linfático en un proceso de muerte celular programada. Sin embargo, y por motivos no bien conocidos, ocasionalmente ese linfocito alterado presenta otros cambios en sus genes que le confieren la capacidad de sobrevivir en el ganglio linfático, escapar al control de las células encargadas de la vigilancia inmunológica y proliferar de forma incontrolada.

El LH se describió por primera vez en 1832 La etiología fue desconocida durante mucho tiempo. En el curso de las últimas dos décadas se ha revelado la naturaleza de las células $B$ y de sus células patognomónicas (denominadas células de Reed-Sternberg [CRS]), junto con varias lesiones genéticas recurrentes. El papel patogénico de la infección por el virus de Epstein-Barr también se ha confirmado. Las CRS en el LH clásico tienen varias características que son inusuales para las células tumorales linfoides y el microambiente del $\mathrm{LH}^{1}$.

El LH es una enfermedad de células B con una distribución bimodal.

En los EE.UU. se diagnostican todos los años alrededor de 9,500 casos nuevos de LH. El cociente sexo masculino:sexo femenino es de 1.4:1. El LH es raro antes de los 10 años de edad y es más frecuente entre los 15 y 40 años; se observa un segundo pico en individuos > 60 años.

Las CRS son derivadas de células germinales del centro $B$ que han adquirido mutaciones de genes de la cadena variable de la inmunoglobulina que han 
sufrido apoptosis. Pocos casos de LH clásico se originan en las células $T$.

Se desconoce la causa, pero intervienen la susceptibilidad genética y las asociaciones ambientales (p. ej., ocupaciones como la carpintería, antecedentes de tratamiento con fenitoína, radioterapia $[\mathrm{RT}]$ o quimioterapia [QT], infecciones por el virus de EpsteinBarr, Mycobacterium tuberculosis, herpes virus tipo 6 y virus de la inmunodeficiencia humana $[\mathrm{VIH}])$. El riesgo es ligeramente mayor en individuos con ciertos tipos de inmunosupresión (p. ej., pacientes trasplantados que reciben inmunosupresores), en individuos con trastornos de inmunodeficiencia congénita (p. ej., síndrome de ataxia telangiectasia, síndrome de Klinefelter, síndrome de Chédiak-Higashi y síndrome de Wiskott-Aldrich) y también en individuos con determinados trastornos autoinmunitarios (artritis reumatoide, enfermedad celiaca, síndrome de Sjögren y lupus eritematoso sistémico).

La mayoría de los pacientes también presentan un defecto lentamente progresivo de la inmunidad celular (función de los linfocitos T) que, en la enfermedad avanzada, contribuye con las infecciones bacterianas frecuentes y las más infrecuentes micóticas, virales y protozoarias. En la enfermedad avanzada se observa una depresión de la inmunidad humoral (producción de anticuerpos). A menudo, la muerte se debe a una infección.

Se debe diagnosticar en biopsia por escisión de un ganglio, a fin de obtener material suficiente para el diagnóstico histopatológico e inmunohistoquímico. Se debe evitar el diagnóstico mediante punción ganglionar con aguja fina, ya que es común que resulte en material insuficiente; este método solo quedará reservado para casos puntuales en los cuales sea imposible la metodología diagnóstica correcta.

Según la clasificación de la Organización Mundial de la Salud, el LH se divide en dos subtipos histopatológicos: clásico (95\%) (esclerosis nodular [40-75\%], celularidad mixta [20-40\%], depleción linfocitaria [5-15\%], rico en linfocitos [5-15\%]) y con predominio linfocítico nodular $(5 \%)^{2}$.

Se ha encontrado múltiples vías de señalización y factores de transcripción que muestran actividad desregulada en las $\mathrm{CRS}$, incluido el factor nuclear $\mathrm{\kappa B}$, Jak, Stat, PI3K, Akt, Erk, AP1 y tirosina cinasas. Las CRS atraen muchas células al tejido del linfoma, lo que resulta en un microambiente inflamatorio típico. Este entorno probablemente promueve la supervivencia de las células malignas que escapan del ataque de las células citotóxicas T o natural killer ${ }^{2,3}$.

\section{Descripción histopatológica}

Como se comentó anteriormente, es indispensable y necesario tomar siempre que sea posible una biopsia de ganglio linfático, los ganglios inguinales no deben de tomarse si existen nódulos periféricos sospechosos. Si el LH se hace con biopsias de un sitio extranodal, una confirmación por biopsia nodular es recomendable a menos que la sospecha de LH sea inequívoca ${ }^{3}$.

La clasificación de LH 2016 no ha presentado cambios notables respecto a la versión del 2008. La excepción a esta primera aseveración tiene que ver con el LH variedad nodular de predominio linfocítico (LHNPL), lo anterior debido a que se ha observado que en el LHNPL pueden existir diferentes patrones de infiltración (p. ej., difuso y/o con predominio de linfocitos T).

EI LHNPL puede progresar a una proliferación rica en linfocitos $T$ carente de células dendríticas foliculares, de acuerdo más con un linfoma de células grandes $B$ rico en histiocitos de células T (THRLBCL, $T$-cell histiocyte-rich $L B C L$ ). Se agregó en la clasificación del 2016, para esta progresión, la condición like (THRLBCL-like) como transformación a partir del LHNPL ${ }^{4}$.

\section{Abordaje inicial}

Dentro de la evaluación clínica inicial se debe interrogar al paciente a propósito de los síntomas $\mathrm{B}$, si existe intolerancia al alcohol (dolor a la ingesta de bebidas alcohólicas), prurito generalizado y astenia/ adinamia. Asimismo, dentro de la exploración física se debe registrar el nivel de desempeño físico y si existen megalias en regiones linfoides, bazo $y / 0$ hígado.

Los estudios de laboratorio necesarios son: la biometría hemática completa, además de velocidad de sedimentación globular, proteína $\mathrm{C}$ reactiva, enzimas hepáticas con albúmina, deshidrogenasa láctica y fosfatasa alcalina, y prueba de embarazo en mujeres en edad fértil. Asimismo, se deberá descartar infección por $\mathrm{VIH}$, hepatitis $\mathrm{B}$ y $\mathrm{C}^{2}$. Es obligatorio valorar el funcionamiento cardiaco (electrocardiograma y ecocardiograma) y pulmonar (espirometría) debido a los riesgos inherentes del tratamiento farmacológico.

En el abordaje de LH habitualmente se debe realizar radiografía de tórax, además de tomografía contrastada de cuello, tórax y abdomen. Sin embargo, el estudio de imagen de elección es la tomografía por 
emisión de positrones-tomografía computarizada (PET-CT) con F18-fluorodesoxiglucosa (FDG) desde la base del cráneo hasta la mitad del muslo. La realización de biopsia de médula ósea (MO) se lleva a cabo para descartar infiltración de esta. En caso de no contar con PET-CT, la tomografía computarizada (TC) basal diagnóstica es el estudio de imagen alternativo ${ }^{3}$.

De acuerdo con los datos actuales, el LH clásico se caracteriza por un inmunofenotipo habitual con la expresión de CD15+, CD30+, PAX-5+ (débil) y negativo para CD3-, CD20-, CD45- y CD79a-.

El inmunofenotipo habitual del LH de predominio linfocitario nodular, que representa el $5 \%$ o menos de todos los linfomas, es con CD20+, C45+, CD79a+, BCL6+, PAX-5+ y negativo para CD3-, CD15- y CD30-.

Los pacientes que inician con enfermedad voluminosa, afectación subdiafragmática o esplénica tienen mayor riesgo de transformación a linfoma de células grandes 3 .

\section{Estadificación}

De acuerdo con la clasificación de Ann Arbor, los síntomas $\mathrm{B}$ consisten en la presencia de cualquiera de los siguientes: fiebre $>38.3^{\circ} \mathrm{C}$, pérdida ponderal y diaforesis nocturna ${ }^{5}$. Los criterios de clasificación fueron establecidos en la 11. ${ }^{a}$ Conferencia de Linfoma Maligno Internacional en Lugano, Suiza, realizada en junio del 2011. En esta reunión de expertos, la PET con FDG fue incorporado de manera formal a la estadificación de linfomas ávidos e FDG, entre ellos el LH. En la conferencia citada se modificó la clasificación previa de Ann Arbor, permaneciendo los sufijos A y B (sintomatología) solo en el LH. La respuesta al tratamiento será valorada por PET mediante la escala de 5 puntos (five-point scale [PS]). Asimismo, el producto de los diámetros perpendiculares de un solo nódulo puede utilizarse para identificar progresión de la enfermedad.

Las recomendaciones de la reunión de Costwold fueron que se incluyera la TC como la técnica de evaluación de nódulos intratorácicos e infradiafragmáticos, los criterios de involucro de bazo e hígado se modificaron, además de que se deberían ignorar las alteraciones de las pruebas de funcionamiento hepático ${ }^{4}$. Se introdujo en esta reunión el sufijo $X$ para definir la enfermedad voluminosa (>10 cm). Por último, se creó la categoría de respuesta completa incierta, en pacientes con alteraciones radiológicas persistentes, aunque con significado clínico incierto. Asimismo, se evidenció el carácter ominoso de la enfermedad voluminosa, estableciéndose que las adenomegalias con diámetro superior a $2.5 \mathrm{~cm}$ son consideradas anormales ${ }^{3}$. Los cortes tomográficos deben de ser de $1 \mathrm{~cm}$.

Se deben de registrar el tamaño de hígado y el del bazo por debajo de línea costal a nivel de línea medioclavicular.

El sufijo $E$ se utiliza en la clasificación clínica cuando el involucro extranodal es contiguo o proximal a la lesión nodal.

Grupos de ganglios linfáticos incluidos en el término mediastinal:

- Prevascular, aortopulmonar.

- Paratraqueal, pretraqueal, subcarinal.

- Mediastinal posterior.

- Considerados fuera del mediastino.

- Nódulos hiliares (broncopulmonares).

- Mamarios internos.

- Paravertebrales, debido a su drenaje en pared torácica y diafragma.

Para ser considerado como masa voluminosa, el nódulo aislado o conglomerado debe de exceder los $10 \mathrm{~cm}$ de diámetro. El tamaño de las lesiones en bazo o hígado no deben utilizarse para fines pronósticos.

En mediastino, la definición de voluminosa se otorga cuando la masa excede o es igual a un tercio del diámetro transverso a nivel T5/6.

Enfermedad nodal:

- Estadio I. Involucro de una sola región o estructura nodal como bazo, timo o anillo de Waldeyer.

- Estadio II. Afectación de dos o más regiones nodales del mismo lado del diafragma. Los nódulos hiliares deben ser considerados como «lateralizados»; por lo tanto, cuando se involucren ambos lados, constituye un estadio II. El número de regiones anatómicas afectadas deberán indicarse con un suscrito (p. ej., $\mathrm{II}_{3}$ ).

- Estadio III. Hay un involucro de regiones nodales o estructuras linfoides a ambos lados del diafragma ${ }^{5}$.

\section{Uso de PET-CT}

De acuerdo con el trabajo en la Fourth International Workshop on PET in Lymphoma en la ciudad de Menton, Francia, se han establecido los lineamientos para estadificación y valoración de la respuesta en linfomas ávidos de FDG ${ }^{6}$. La PS fue propuesta y recomendada en el First International Workshop on PET in Lymphoma (Deauville, Francia) en $2009^{6}$. En este 
trabajo de Barrington, et al. se establecieron los criterios para el uso de PET en el contexto clínico de linfomas (incluido el LH) y ensayos de fase tardía. Esta clasificación no tiene una buena sensibilidad para infiltración a sistema nervioso central, por lo que se prefiere la resonancia magnética (RM) en caso de sospecha de infiltración a dicho nivel ${ }^{6}$. La intensidad de la captación se reporta de acuerdo con la escala SUV (standardized uptake value). El score de 5 puntos de Deauville es como se establece en la tabla 1.

Las puntuaciones 1 y 2 son consideradas como respuesta metabólica completa, mientras que una puntuación de 3 se considera respuesta metabólica completa solo en PET intermedia ${ }^{4,6}$.

En la PET interina (PETi) las puntuaciones de $4 \mathrm{y}$ 5 se consideran como respuesta metabólica parcial, aunque en PET al final del tratamiento se considera enfermedad metabólica residual ${ }^{6}$.

La PETi tiene como propósito asegurar la efectividad del tratamiento excluyendo la posibilidad de progresión. Lo anterior, debido a que la respuesta metabólica (mostrada por PET) es más temprana que la anatómica. Se ha demostrado que la PETi supera el valor pronóstico del IPS (International Prognostic Index). El valor predictivo negativo es del $95 \%$ para la PETi en LH en $\geq 2$ años de supervivencia libre de progresión (SLP), con un valor productivo positivo aceptable, con SLP del 13 al 27\%5,6.

La captación hepática de FDG puede estar influenciada por los niveles glucémicos y de insulina; por otro lado, la captación en MO y bazo se afectaría por QT o uso de factor estimulante de crecimiento de colonias en granulocitos (FEC-G).

Se realizará $P E T$ al menos tres semanas después de la última aplicación de QT, aunque preferentemente después de seis a ocho semanas, dos semanas después de uso de FEC-G y tres meses luego de que la RT se completó6.

\section{PET al final del tratamiento}

La PET para valoración de remisión al final del tratamiento tiene alta precisión en el LH, mayor que la TC. Se ha reportado esta alta precisión posterior a esquemas ABVD (doxorubicina [adriamicina], bleomicina, vinblastina y dacarbazina) y BEACOPP (bleomicina, etopósido, doxorubicina [adriamicina], ciclofosfamida, vincristina [Oncovin ${ }^{\circledast}$ ], procarbazina y prednisona) en LH avanzado. En caso de masa residual a pesar de respuesta metabólica completa, algunos autores argumentan que la masa residual carece de significancia
Tabla 1. Score de 5 puntos de Deauville

Score de 5 puntos de Deauville

1. Sin captación

2. Captación $\leq$ mediastino

3. Captación > mediastino, pero $\leq$ hígado

4. Captación moderadamente mayor que hígado (se sugiere que sea mayor que la máxima SUV de una región considerable de hígado normal)

5. Captación marcadamente mayor que hígado y/o nuevas lesiones (2 a 3 veces mayor que el SUV máximo hepático)

$X$. Nuevas áreas de captación probablemente no relacionadas a linfoma

SUV: standardized uptake value.

clínica, mientras que otros sugieren combinar con documentación de remisión radiológica ${ }^{5,6}$.

En los últimos años el aporte de la PET en la evaluación de la respuesta ha permitido identificar un grupo de pacientes de excelente pronóstico en los que es factible la omisión de la RT.

La evaluación se basa en la escala visual de 5 puntos de Deauville descrita anteriormente, la cual considera:

- Respuesta metabólica completa. Puntuación 1, 2 y 3 en sitios nodales o extranodales con 0 sin masa residual por PET.

- Respuesta metabólica parcial. Persistencia de lesiones metabólicas, pero con menor metabolismo en comparación al basal.

- Sin respuesta metabólica. Puntuación 4 y 5 sin cambios con respecto a la PET basal, ya sea en la PETi o la PET al fin del tratamiento.

- Enfermedad metabólica progresiva. Puntuación 4 y 5 con aumento de la captación con respecto a la PET basal.

Esto se debe considerar tanto para la PETi como para la PET de fin del tratamiento.

Una puntuación de 3 significa buena respuesta y buen pronóstico en la mayoría de los pacientes. Sin embargo, en aquellos protocolos que utilizan la PET para desescalar el tratamiento ${ }^{7,8}$.

Particular importancia y relevancia ha tomado la $\mathrm{PET} / \mathrm{CT}$ interina por lo evidenciado en el ensayo RATHL (Response-Adapted Therapy in Avanced Hodgkin Lymphoma), donde hubo reestadificación a la alza de acuerdo con la PET, comparado con la TC y biopsia de $\mathrm{MO}$ en 159 pacientes (el 14\% de la muestra). El seguimiento de los resultados discrepantes confirmó los hallazgos de la PET-CT en la mayoría de los pacientes, lo que indica la superioridad de la PET-CT con respecto a la TC y la biopsia de $\mathrm{MO}^{7-9}$. 


\section{Tratamiento}

Previo al inicio del tratamiento de LH es necesario hacer hincapié en los efectos secundarios, que pueden ser no reversibles.

Se deberá informar al paciente de que los fármacos utilizados en QT tienen riesgo de provocar infertilidad permanente. Por lo que, en caso de que el paciente lo solicite, se deberá favorecer la criopreservación de semen, fertilización in vitro, o preservación de tejido ovárico o criopreservación de ovocitos y ooforopexia, de acuerdo con el caso en cuestión.

Es prioritario contar con pruebas de función respiratoria, incluida la capacidad de difusión de monóxido de carbono (DLCO) si se utilizará esquema ABVD o BEACOPP debido a la elevada toxicidad pulmonar de la bleomicina en pacientes susceptibles. Una DLCO $>60 \%$ es aceptable para el uso de bleomicina ${ }^{9,10}$.

En caso de que se contemple RT a bazo, el paciente deberá contar con esquema de vacunación contra neumococo, Haemophilus influenzae y meningococo.

Los esquemas de tratamiento se muestran en la tabla $2^{4,9}$.

El algoritmo de tratamiento dependerá de si se trata de LH clásico o de predominio linfocítico, si es un estadio temprano con marcadores de pronóstico desfavorables o no, el esquema inicial de manejo y si existe enfermedad voluminosa, entre las variables más relevantes.

En lo que se respecta a pacientes con estadio temprano (l 0 II) sin factores de mal pronóstico (desfavorables), se propone el algoritmo que se muestra en la figura 1. En caso de que solo se desee utilizar QT en estadio tempranos de Linfoma Hodgkin clásico (LHc), se podrán administrar dos ciclos de ABVD y reestadificarse con PET-CT. Los pasos subsecuentes dependerán de la puntuación Deauville.

También se pueden manejar los pacientes con enfermedad en estadio temprano de bajo riesgo con el esquema Stanford V (clormetina, doxorubicina, vinblastina, vincristina, bleomicina, etopósido y prednisona), ocho semanas de manejo. Posteriormente, se reestadificará con $\mathrm{PET}$-CT.

- D 1-4: Radioterapia a sitio afectado con 30 Gy.

- D 5: se tomará biopsia de región afectada. De ser negativa se optará por conducta en D 1-4. Si es positiva, se llevará a cabo manejo de enfermedad refractaria.

\section{Estadio temprano (I-II) con factores desfavorables sin enfermedad voluminosa}

En caso de decidirse esquema ABVD, se indicarán dos ciclos iniciales. Posteriormente se valorará con PET-CT para decidir manejo posterior. De acuerdo con la puntuación de Deauville:

- D 1-2

- Dos ciclos de ABVD (total 4) + RTSP.

- O cuatro ciclos más de AVD (total seis ciclos, últimos cuatro sin bleomicina).

- D 3-4:

- Dos ciclos ABVD (total 4) (solo considerar D 3).

- Dos ciclos de BEACOPP escalado (preferentemente D 4).

- D 5: se deberá biopsiar la región afectada.

- De ser negativa la biopsia se aplicarán cuatro ciclos más (total seis ciclos) con o sin RTSP.

- En biopsia positiva se considerará refractario.

- Por otro lado, si se decide esquema Stanford, se aplicarán 12 semanas de Stanford V. Otro esquema por utilizarse es el BEACOPP dos ciclos y dos ciclos más de ABVD con RTSP como consolidación en pacientes menores a 60 años.

\section{En pacientes con enfermedad localizada con enfermedad voluminosa}

Se trata de los pacientes con enfermedad temprana/localizada (estadios I y II) con factores pronósticos desfavorables con enfermedad voluminosa a nivel mediastinal 0 adenopatías $>10 \mathrm{~cm}$. Las alternativas de manejo inicial:

- ABVD dos ciclos.

- Reestadificación con PET-CT.

- D 1-2: ABVD dos ciclos más (total cuatro), o AVD cuatro ciclos más (seis totales). En ambos casos con o sin RTSP.

- D 3-4: ABVD dos ciclos más (total cuatro) de manera preferente para $D$ 3. Por otro lado, para un 4 se sugiere BEACOPP escalado en dos ciclos. En ambos casos (D 3 y 4) se administrarán 30 Gy posteriormente como RTSP. Otra alternativa independientemente de ser D 3-4, es administrar tres ciclos de BEACOPP escalado con PET-CT posterior y nuevo ciclo BEACOPP para finalizar (cuatro BEACOPP y dos ABVD iniciales).

- Doce semanas de esquema Stanford V. 
Tabla 2. Esquemas de tratamiento

\begin{tabular}{|c|c|c|c|}
\hline \multicolumn{4}{|c|}{ Esquemas de primera línea } \\
\hline Nombre del esquema & Dosis & $\begin{array}{c}\text { Vía de } \\
\text { aplicación }\end{array}$ & Días que aplicarse \\
\hline $\begin{array}{l}\text { ABVD } \\
\text { Doxorubicina (adriamicina) } \\
\text { Bleomicina } \\
\text { Vinblastina } \\
\text { Dacarbazina }\end{array}$ & $\begin{array}{c}25 \mathrm{mg} / \mathrm{m}^{2} \\
10 \mathrm{Ul} / \mathrm{m}^{2} \\
6 \mathrm{mg} / \mathrm{m}^{2} \\
375 \mathrm{mg} / \mathrm{m}^{2}\end{array}$ & $\begin{array}{l}\text { IV } \\
\text { IV } \\
\text { IV } \\
\text { IV }\end{array}$ & $\begin{array}{l}1 \text { y } 15 \\
1 \text { y } 15 \\
1 \text { y } 15 \\
1 \text { y } 15\end{array}$ \\
\hline $\begin{array}{l}\text { BEACOPP escalado } \\
\text { Bleomicina } \\
\text { Etopósido } \\
\text { Doxorubicina (adriamicina) } \\
\text { Ciclofosfamida } \\
\text { Vincristina } \\
\text { Procarbazina } \\
\text { Prednisona } \\
\text { FEC-G }\end{array}$ & $\begin{array}{c}10 \mathrm{Ul} / \mathrm{m}^{2} \\
200 \mathrm{mg} / \mathrm{m}^{2} \\
35 \mathrm{mg} / \mathrm{m}^{2} \\
1,250 \mathrm{mg} / \mathrm{m}^{2} \\
1.4 \mathrm{mg} / \mathrm{m}^{2} \mathrm{~B} \\
100 \mathrm{mg} / \mathrm{m}^{2} \\
40 \mathrm{mg} / \mathrm{m}^{2}\end{array}$ & $\begin{array}{l}\text { IV } \\
\text { IV } \\
\text { IV } \\
\text { IV } \\
\text { IV } \\
\text { VO } \\
\text { VO } \\
\text { SC }\end{array}$ & $\begin{array}{c}8 \\
1 \text { a } 3 \\
1 \\
1 \\
8 \\
1-7 \\
1-14 \\
\text { Desde el día } 8\end{array}$ \\
\hline $\begin{array}{l}\text { Stanford V (aplicaciones semanales por } 8 \text { semanas) } \\
\text { Mecloretamina } \\
\text { Doxorubicina (adriamicina) } \\
\text { Vinblastina } \\
\text { Vincristina } \\
\text { Bleomicina } \\
\text { Etopósido } \\
\text { Prednisona }\end{array}$ & $\begin{array}{c}6 \mathrm{mg} / \mathrm{m}^{2} \\
25 \mathrm{mg} / \mathrm{m}^{2} \\
6 \mathrm{mg} / \mathrm{m}^{2} \\
1.4 \mathrm{mg} / \mathrm{m}^{2}(\mathrm{máxima} \text { dosis } 2 \mathrm{mg}) \\
5 \mathrm{Ul} / \mathrm{m}^{2} \\
60 \mathrm{mg} / \mathrm{m}^{2} \\
40 \mathrm{mg} / \mathrm{m}^{2}\end{array}$ & $\begin{array}{l}\text { IV } \\
\text { IV } \\
\text { IV } \\
\text { IV } \\
\text { IV } \\
\text { IV } \\
\text { VO }\end{array}$ & $\begin{array}{c}\text { Semanas } 1 \text { y } 5 \\
\text { Semanas 1, 3, } 5 \text { y } 7 \\
\text { Semanas 1, 3, } 5 \text { y } 7 \\
\text { Semanas 2, 4, } 6 \text { y } 8 \\
\text { Semanas 2, 4, } 6 \text { y } 8 \\
\text { Semanas (2 días) } 3 \text { y } 7\end{array}$ \\
\hline
\end{tabular}

*Se administrará en días alternos a la dosis mencionada durante las primeras 6 semanas, posteriormente se disminuirá la dosis a 10 mg al día en las últimas 2 semanas.

FEC-G: factor estimulante de colonias de granulocitos; IV: intravenoso; VO: vía oral; SC: subcutáneo.

Adaptada de Eichenauer, et al., $2017^{4}$ y Advani, et al., $2013^{\circ}$.

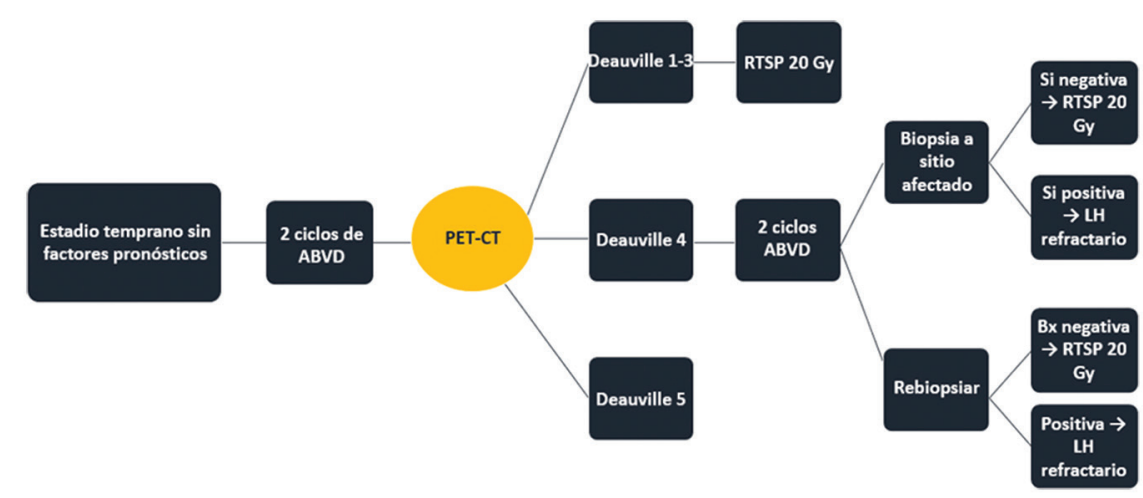

Figura 1. Algoritmo de tratamiento para pacientes con estadio temprano (I o II) sin factores de mal pronóstico (desfavorables).

ABVD: doxorubicina (adriamicina), bleomicina, vinblastina y dacarbazina; PET-CT: tomografía por emisión de positrones-tomografía computarizada; RTSP: radioterapia a sitio afectado; LH: linfoma de Hodgkin; Bx: biopsia.

- Dos ciclos de BEACOPP escalado con dos ciclos ABVD, posteriormente con RTSP.

- En caso de elegirse esquema Stanford V, posterior a la finalización de las 12 semanas, se restadificará con PET-CT.

- D 1-4: RTSP a sitios iniciales con tamaño superior a $5 \mathrm{~cm}$.
- D 5: biopsia, de ser negativa se indicará RTSP a los sitios mencionados. En caso de ser positiva se manejará como enfermedad refractaria.

Se puede elegir el esquema BEACOPP desde el inicio en pacientes con estadios I y II, con características desfavorables, sean de enfermedad voluminosa o no. En este caso se aplicarán dos ciclos y 
posteriormente dos ciclos de esquema ABVD. En la reestadificación con PET-CT:

- D 1-4: RTSP.

- D 5: debe realizarse nueva biopsia. De ser negativa se realizará RTSP. En caso de positividad se considerará como enfermedad refractaria.

\section{Valoración de respuesta}

Una evaluación diferente de PET-CT es la obtenida por TC. Definiciones según lo publicado en la reunión de Cotswold meeting:

- Respuesta completa (RC): paciente sin evidencia de LH clínica, radiológica o cualquier otra ${ }^{3}$.

- Respuesta completa no confirmada/incierta. Paciente con adecuado estado de salud, sin evidencia clínica de LH, pero con alguna anormalidad radiológica, no consistente con los efectos de la terapia, la cual persiste en el sitio de la enfermedad previa ${ }^{5,10}$.

- Respuesta parcial (RP): disminución de al menos el $50 \%$ de la suma de los productos del mayor diámetro perpendicular de las lesiones medibles. Asimismo, debe de existir una remisión de los síntomas $\mathrm{B}^{5,11}$.

- Progresión de enfermedad: se trata de un incremento $\geq 25 \%$ en el tamaño de una lesión medible o aparición de nuevas lesiones o recurrencia de los síntomas B, los cuales no pudieran explicarse por alguna otra causa ${ }^{9-11}$.

- PS de un sitio en específico debe denotarse por el suscrito de este (p. ej., $\mathrm{M}=$ médula ósea, $\mathrm{H}=$ hígado, $L=$ pulmón, $\mathrm{O}=$ hueso, $\mathrm{P}=$ pleura, $\mathrm{D}=$ piel).

\section{Comparación de Stanford V vs. ABVD}

Gordon, et al. compararon la supervivencia global (SG) entre pacientes manejados con Stanford $V$ y tratados con ABVD en LHc en su primera línea de tratamiento (Fig. 2) ${ }^{8}$. El estudio fue conducido por el Eastern Cooperative Oncology Group (ECOG), Cancer and Leukemia Group B, Southwest Oncology Group, Canadian NCIC Clinical Trials Group. Con una mediana de edad de 33 años en ambos grupos y el 24.6-26.4\% de pacientes en estadio IV, el ABVD permaneció como el estándar de tratamiento al lograr una RC de 73 vs. $69 \%$ del Stanford V ${ }^{8}$. Finalmente, con un seguimiento de 6.4 años, la supervivencia libre de falla a tratamiento (SLFT) fue del $74 \%$ en ABVD y del $71 \%$ en el grupo de Stanford $V$ a cinco años $(p=0.32)^{12}$.

\section{Brentuximab vedotin}

El brentuximab vedotin (BV) es un anticuerpo conjugado IgG1 quimérico dirigido contra CD30, anticuerpo el cual se halla unido de manera covalente al agente de disrupción de microtúbulos monometil auristatina $\mathrm{E}$. El BV logra por sí solo respuesta global (RG) del 75\% con RC del $34 \%$ en pacientes previamente tratados ${ }^{10}$. Previo al estudio de O'Connor ${ }^{9}$, el BV estaba aprobado solo posterior a Trasplante autologo de progenitores hematopoyeticos (TACPH) o refractario $a \geq 2$ líneas de tratamiento. O'Connor, et al. valoraron la seguridad y actividad de la combinación BV+bendamustina en pacientes previamente tratados con LH Recaida/ Refractarios (R/R) y linfoma de células grandes $T$ anaplásico. Los autores realizaron un estudio internacional multicéntrico fase 1-2 llegando a la conclusión que la dosis de BV a administrarse sería de $1.8 \mathrm{mg} / \mathrm{kg}$ y $90 \mathrm{mg} / \mathrm{m}^{2}$ de bendamustina que aplicarse cada tres semanas. Con ello se logró una RG del $78 \%$ (intervalo de confianza [IC] 95\%: 62-91). Los eventos adversos fueron neumonía grado 3 y neutropenia grado 3-4 en el 14 y el $25 \%$, respectivamente ${ }^{12,13}$.

Por otro lado, LaCasce, et al. evaluaron la combinación de BV+bendamustina en un estudio de fase 1-2 en LH R/R luego de primera línea de tratamiento (Fig. 3$)^{13}$. En un total de 55 pacientes con una mediana de edad de 36 años, el $50.9 \%$ fue primariamente refractario y el $49.1 \%$ en recaída. Fueron administrados por lo menos dos ciclos antes de TACPH. En caso de realizarse 0 no el trasplante, los pacientes podían recibir un total de 16 ciclos de monoterapia de BV. La RG observada fue del 92.5 y el $73.6 \%$ de $\mathrm{RC}^{14}$.

Por otro lado, en el ensayo AETHERA se estudió el BV como opción de consolidación en pacientes con LHc de riesgo alto de recaída o progresión posterior a trasplante autologo de progenitores hematopoyeti$\cos$ (TACPH) (Fig. 4) $)^{12}$. La dosis de BV fue de $1.8 \mathrm{mg} /$ $\mathrm{kg}$ cada tres semanas hasta 16 aplicaciones. El beneficio del BV se continuó mostrando a cinco años con una SLP del $59 \%$ en BV vs. 41 con placebo. Los factores de riesgo estipulados fueron: recaída en menos de 12 meses o refractariedad al tratamiento inicial, la mejor respuesta fue la parcial o enfermedad estable (EE) a la última línea de tratamiento, enfermedad extranodal a la recaída previa a TACPH, o $\geq$ 2 tratamientos de rescate previos ${ }^{15}$. En pacientes con dos 0 más factores de riesgo el grupo BV presentó una mejor SLP que el grupo de placebo (hazard ratio [HR]: 0.424; IC 95\%: 0.30-0.59) ${ }^{15}$. 

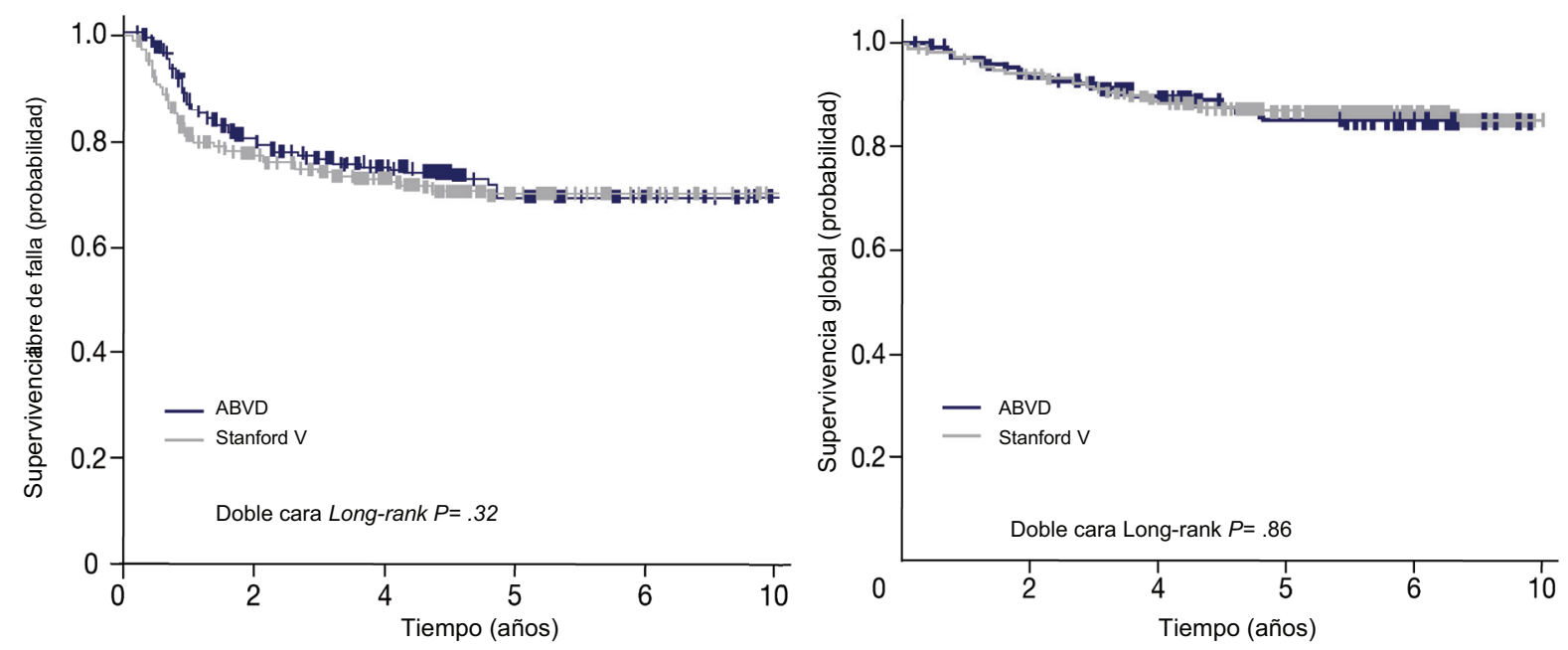

Figura 2. Comparación de la SG entre pacientes manejados con Stanford V frente a los tratados con ABVD en LHc en su primera línea de tratamiento (tomada de Gordon, et al., 2013 ${ }^{10}$ ).

Stanford V: clormetina, doxorubicina, vinblastina, vincristina, bleomicina, etopósido y prednisona; SG: supervivencia global; ABVD: doxorubicina (adriamicina), bleomicina, vinblastina y dacarbazina; LHc: linfoma Hodgkin clásico.

Asimismo, el BV también se ha combinado con esquemas como Dexametasona, dosis altas de citarabina, cisplatino (DHAP) y Etoposido,metilprednisolona, citarabina y cisplatino( ESHAP) (en este caso con RG del $96 \%$ y una $\mathrm{RC}$ del $70 \%)^{16}$.

Los efectos adversos más comunes del BV son neuropatía periférica sensitiva, náuseas, astenia, neutropenia y diarrea ${ }^{14,15}$. La neuropatía se encuentra en relación con la exposición prolongada al fármaco. No obstante, aproximadamente un $80 \%$ de los pacientes presentará una resolución de la neuropatía o mejoría una vez que BV se suspenda ${ }^{16,17}$.

En pacientes en quienes se ha usado BV como puenteo para TAutoPH, la SLP a dos años posterior a TACPH fue del $67 \%$ y la SG del $93 \%$. Por lo que el BV como tratamiento de puenteo en segunda línea de tratamiento previo a trasplante es una terapia promisoria $^{15,17}$.

Por otro lado, se ha observado que en pacientes con ausencia de respuesta $(D \geq 3)$ posterior a dos ciclos de BV, la posibilidad de alcanzar respuesta después de más ciclos de BV como monoterapia es prácticamente nula ${ }^{16}$. Teniendo en cuenta lo anterior, Moskowitz, et al. estudiaron el BV como tratamiento adaptado a PET seguido de Ifosfamida Carboplatino y Etoposido (ICE) aumentado (ICEa) (Fig. 5). Los pacientes estudiados fueron $\mathrm{LH} \mathrm{R} / \mathrm{R}$ posterior a tratamiento con regímenes que contuvieran antraciclinas. Posterior a dos ciclos de $1.2 \mathrm{mg} / \mathrm{kg}$ de BV de aplicación semanal por tres dosis, en ciclos de 28 días, se

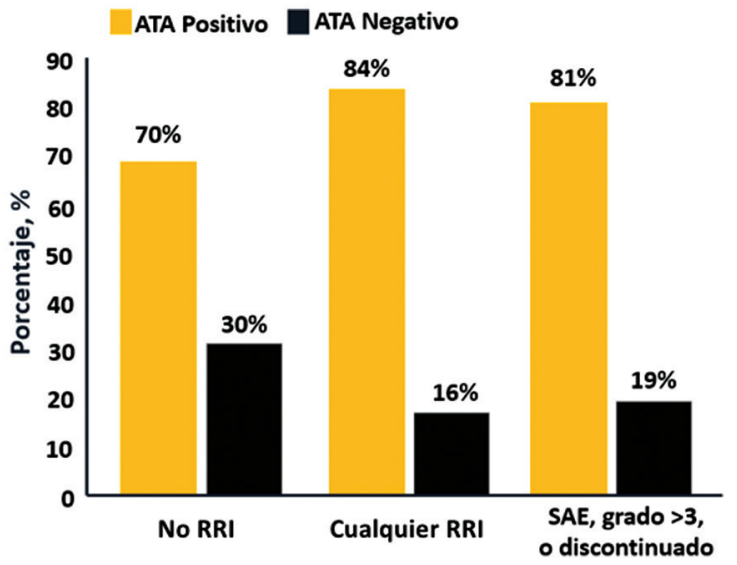

Figura 3. Relación de reacciones asociadas a la infusión y EAS de acuerdo con el status de ATA (tomada de LaCasce, et al., 2018 ${ }^{14}$ ).

EAS: eventos adversos secundarios; ATA: anticuerpo antiterapéutico; $R R I$ : Reacción relacionada con la infusión.

realizó PET-CT. Si la PETi era negativa (D 1 o 2) se procedió a trasplante autólogo. En caso de PETi positiva se administrarían dos ciclos de ICE aumentado (ifosfamida $5,000 \mathrm{mg} / \mathrm{m}^{2}$, mesna $5,000 \mathrm{mg} / \mathrm{m}^{2}$, carboplatino con AUC 5, y etopósido $200 \mathrm{mg} / \mathrm{m}^{2}$ cada $12 \mathrm{~h}$ el primer día $)^{18}$. Doce de 45 pacientes alcanzaron PETi negativa y fueron trasplantados. De los 33 restantes, 32 aceptaron ICEa con 22 de ellos alcanzando negativización del PET al finalizar el tratamiento con posterior $\mathrm{TACPH}^{16}$. La supervivencia libre de enfermedad fue similar en ambos grupos trasplantados, tanto en quienes respondieron a solo dos aplicaciones de BV como monoterapia como a quienes se sometió a ICEa 


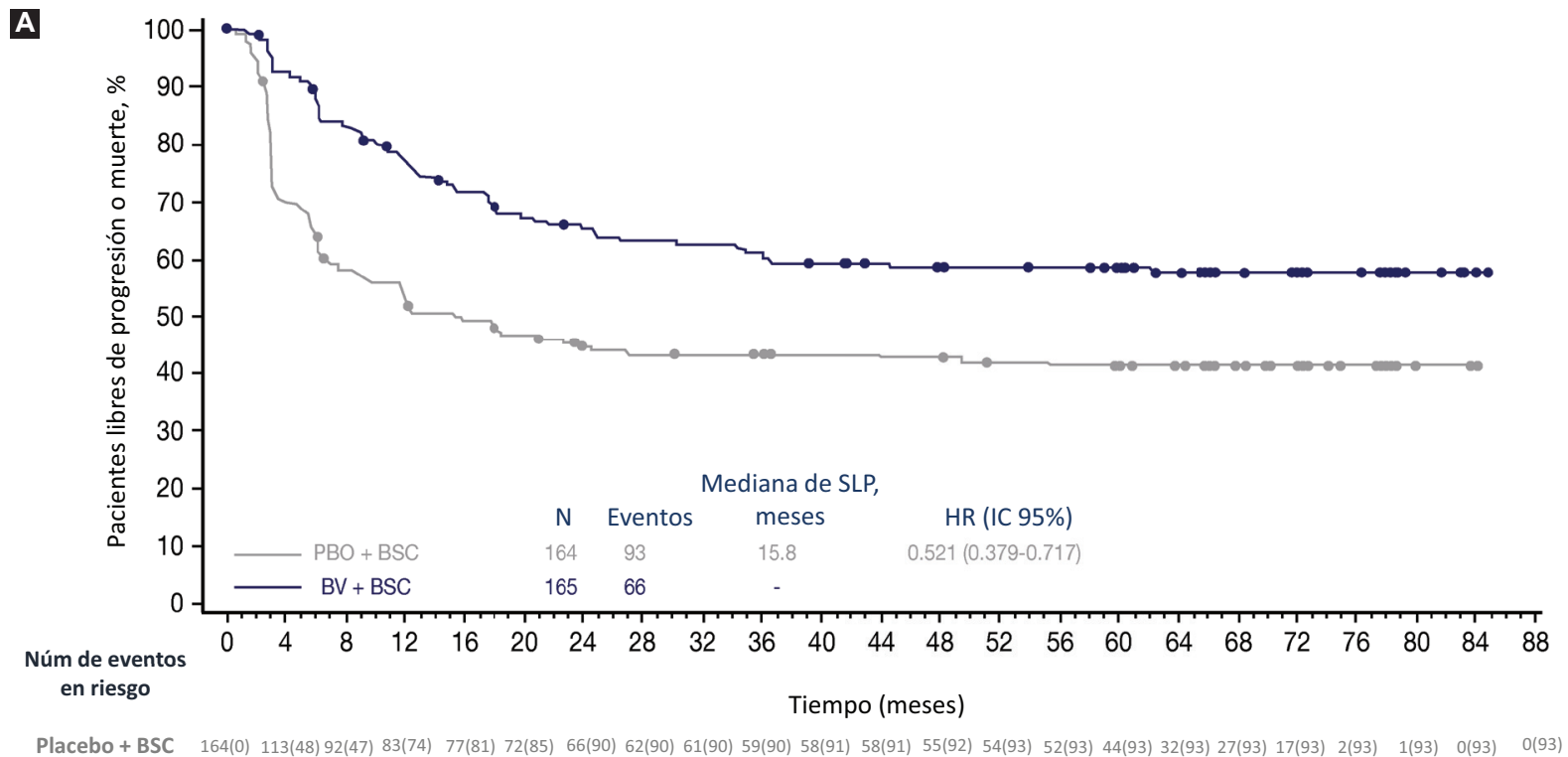

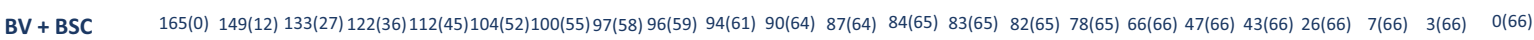

Núm de eventos en riesgo (>2 factores de riesgo)

Placebo + BSC

BV + BSC

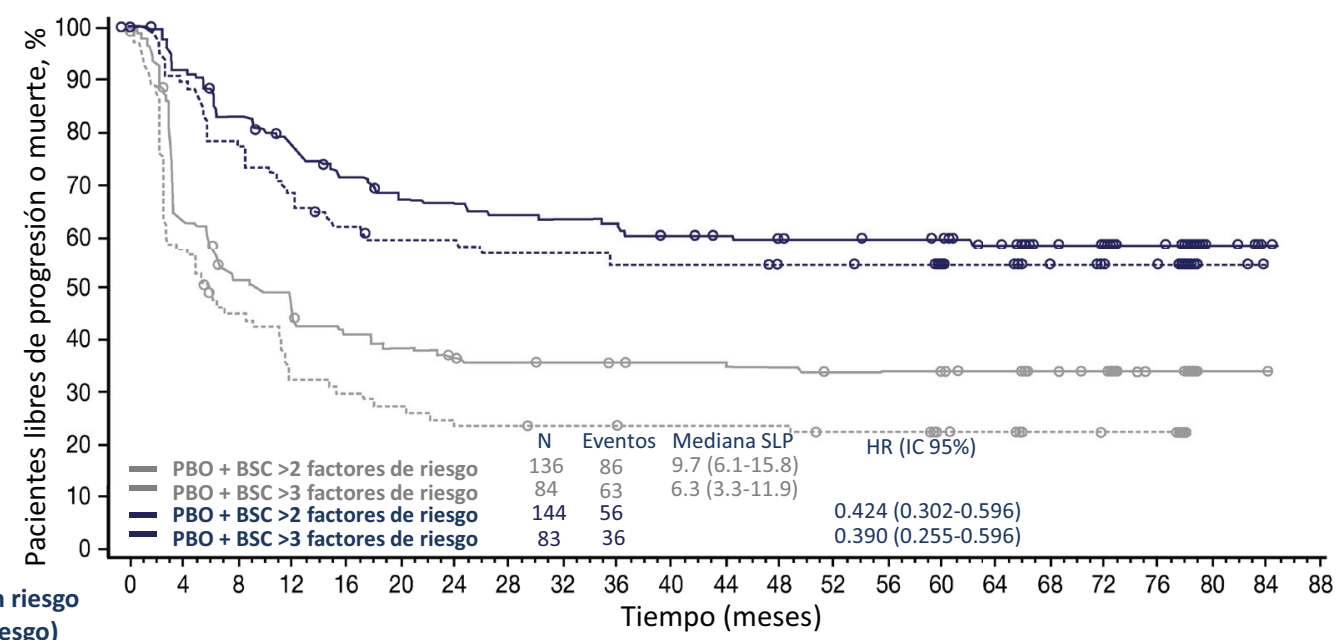

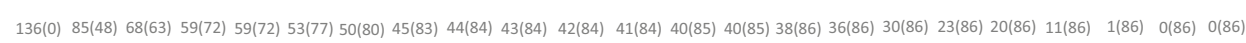

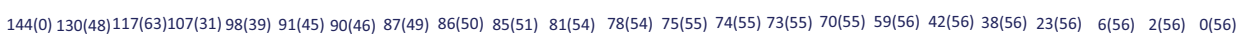

Núm de eventos en riesgo

(>3 factores de riesgo)

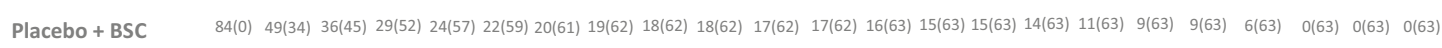

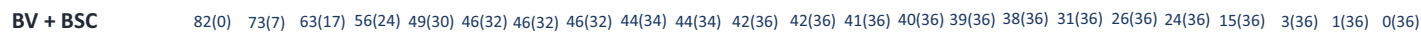

Figura 4. A: supervivencia a cinco años en pacientes con dos o más factores de riesgo. B: SLP comparativa entre grupo PBO con el BSC frente a BV, con $\geq 20 \geq 3$ factores de riesgo (tomada de Moskowitz, et al., 2018 15 ).

SLP: supervivencia libre de progresión; PBO: placebo; BSC: mejor tratamiento de soporte (best suportive care); BV: brentuximab vedotin.

previo a trasplante autologo de progenitores hematopoyeticos $(\mathrm{TACPH})^{15,16}$.

\section{BV COMO PRIMERA LÍNEA}

De manera global, en pacientes manejados con ABVD o Stanford $V$, la mortalidad a cinco años en mayores de 60 años fue del $21 \%$ por progresión del LH, del $9 \%$ relacionada con toxicidad del tratamiento y del $12 \%$ debida a otras causas. En el primer año posterior al diagnóstico de LH, la mortalidad asociada a toxicidad excede a la de progresión en este grupo etario. Se espera que la incidencia de $\mathrm{LH}$ en pacientes mayores de 60 años se incremente hasta el $70 \%$ en 2030. 


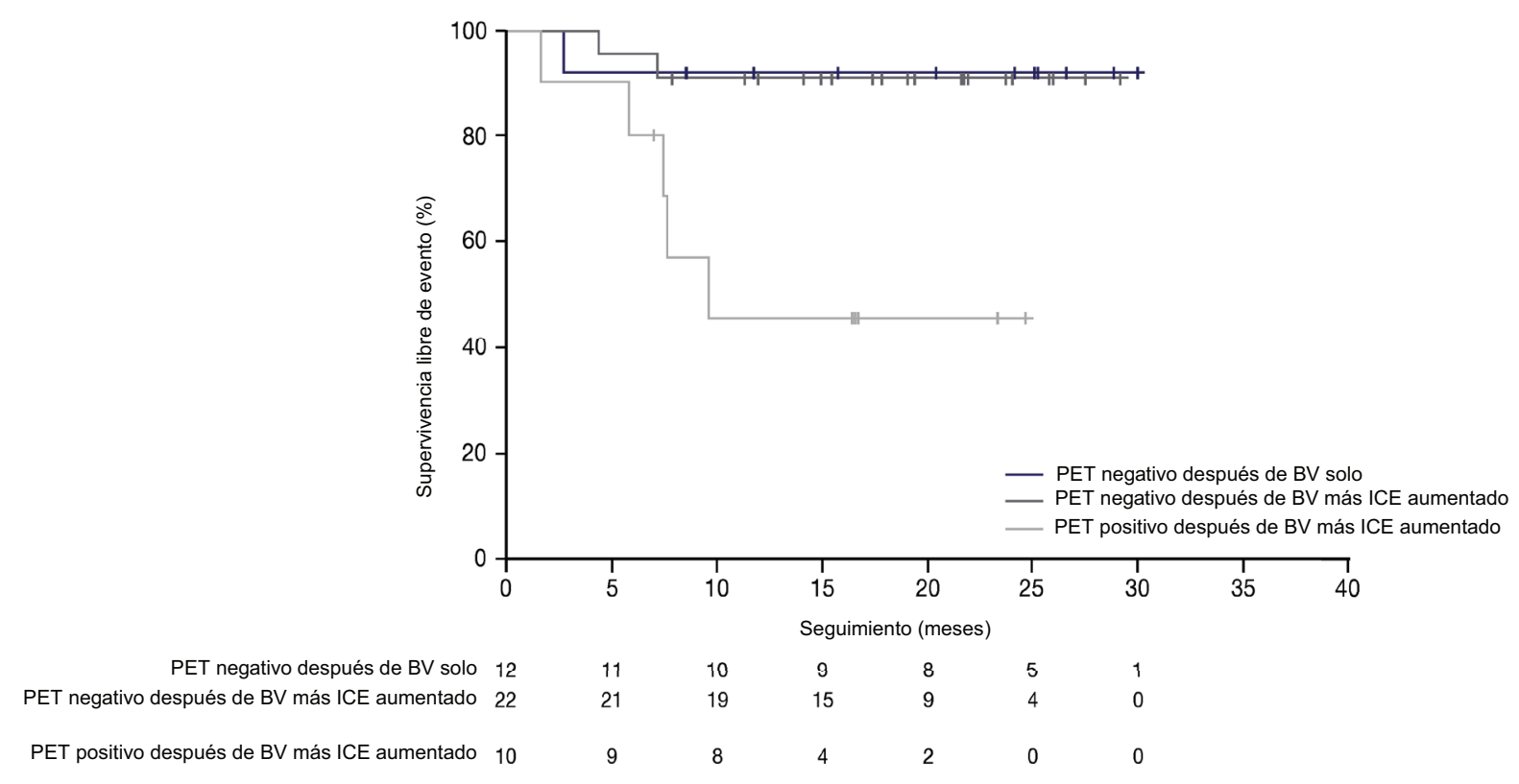

Figura 5. BV como tratamiento (tomada de Moskowitz, et al., 2015 ${ }^{19}$ ). BV: brentuximab vedotin; PET: tomografía por emisión de positrones.

Se trata de un estudio fase 2, para valorar la seguridad y eficacia del BV como tratamiento de primera línea en pacientes $\geq 60$ años. Con una mediana de edad de 78 años en el presente estudio, hasta un 19\% de los pacientes (total 27) fueron mayores de 84 años de edad ( $63 \% \geq 75$ años), con un $22 \%$ con grado $2 / 3$ en la escala del ECOG. La respuesta objetiva se observó en el $92 \%$, con el $73 \%$ de los pacientes alcanzando RC. Todos los pacientes presentaron EE o una mejor respuesta. La SLP fue de 10.5 meses (2.6-22.3 meses), además de una mediana de duración de la RP de 9.1 meses (2.8 a 20.9 meses), la mediana de SG no fue alcanzada. Los efectos adversos más frecuentemente reportados fueron neuropatía periférica sensitiva (78\%), astenia (44\%) y náuseas (44\%), los cuales fueron grado 2 en la mayoría de los pacientes. El G3 de neuropatía sensorial se observó en el $30 \%$ de los pacientes, con mayor riesgo en aquellos con diabetes mellitus y/o hipotiroidismo.

Younes, et al. valoraron la eficacia clínica del BV como primera línea en combinación con tratamiento estándar o modificado en LH (Fig. 6). Los requisitos de inclusión fueron $\mathrm{LH}$ de reciente diagnóstico, CD30+, con estadio clínico IIAx o IIB-IV y ECOG $\leq 2^{17}$. El objetivo primario fue evaluar la seguridad $y$ establecer la dosis máxima tolerada ${ }^{17}$. El $95 \%$ de los pacientes con la combinación BV+ABVD alcanzó RC, mientras que también lo hizo el $96 \%$ del grupo
$\mathrm{BV}+\mathrm{AVD}^{17}$. En el primer grupo, un 44\% presentó toxicidad pulmonar, lo cual no ocurrió en alguno de los pacientes BV+AVD, a pesar de que el $45 \%$ presentaba estadio IV y el $25 \%$ un IPS de 4 o más puntuación. Otro punto a favor del esquema fue que el PETi (después del $2 .{ }^{\circ}$ ciclo) fue negativo en el $96 \%$ de los pacientes en comparación con el $70-85 \%$ en lo reportado de la literatura para ABVD convencional ${ }^{17,18}$.

Otro esquema incorpora BV, A+AVD. En este estudio fase 3, el ensayo ECHELON-1, mostró mejor SLP en A+AVD en comparación con ABVD en LHc estadios III y IV (Fig. 7). Fue un estudio global con el 39\% de pacientes procedentes de Norteamérica (Canadá y EE.UU.), el $50 \%$ de Europa y el $11 \%$ de Asia, pacientes con $\mathrm{LHC}$ con ECOG $\leq 2$. Se compararon 250 pacientes en el grupo A+AVD y 247 en el ABVD. Se observó una SLP con HR de $0.60(p=0.012)$ en quienes recibieron A+AVD. En cuanto a los efectos adversos, la neutropenia febril se observó en el $20 \%$ de A+AVD y el $9 \%$ de ABVD, neuropatía periférica 80 vs. $56 \%$ en el grupo control. No obstante, la toxicidad pulmonar fue menor en A+AVD (solo 3\%) que en ABVD (10\%) $)^{19,20}$.

En el estudio ECHELON-1 la combinación de BV con ABVD omitiendo la bleomicina logró $\mathrm{RC}$ en el $95 \%$ de los casos (45/47 pacientes). Se observó que el BV exacerbaba la toxicidad provocada de la bleomicina al combinarse con ABVD; concluyéndose que no debe combinarse BV con bleomicina ${ }^{20}$. 


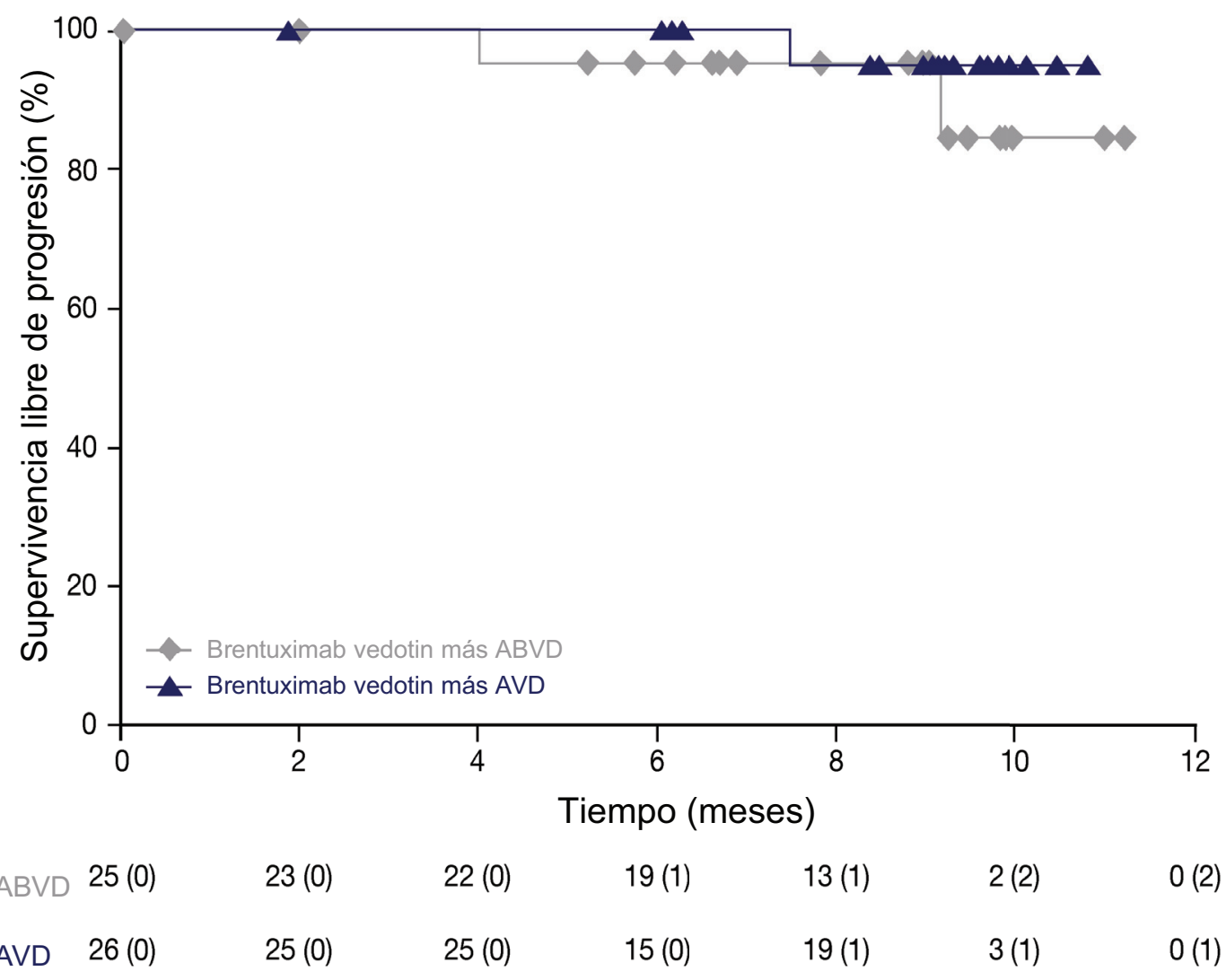

Figura 6. Valoraron la eficacia clínica del BV como primera linea en combinación con tratamiento estándar o modificado en LH (tomada de Younes, et al., 201320).

ABVD: doxorubicina (adriamicina), bleomicina, vinblastina y dacarbazina; AVD: doxorubicina (adriamicina), vinblastina y dacarbazina.

Por otro lado, el uso concomitante de RT a mediastino por enfermedad voluminosa y BV previo no incrementó el riesgo de toxicidad pulmonar ${ }^{13,19,20}$. En este ensayo, los 26 pacientes manejados con esquema $\mathrm{BV}+\mathrm{AVD}$ permanecieron en $\mathrm{RC}, 24$ en la primera remisión y 2 restantes en la segunda. La SLP y SG en el brazo BV+ABVD fue del 79 y $92 \%$, mientras que en $B V+A V D$ fue del 92 y $100 \%$ de manera respectiva ${ }^{13,20}$.

\section{Radioterapia}

En un estudio multicéntrico aleatorizado con pacientes con diagnóstico de LH en estadio temprano y pronóstico favorable ${ }^{18}$. Se establecieron cuatro grupos de dos intensidades de QT diferente y dos dosis diferentes de RT (Figs. 8-10):

- Grupo 1: ABVD 4 ciclos + 30 Gy de RT.

- Grupo 2: ABVD 4 ciclos + 20 Gy de RT.

- Grupo 3: ABVD 2 ciclos + 30 Gy de RT.

- Grupo 4: ABVD 2 ciclos + 20 Gy de RT.

- Las dos dosis de QT no mostraron diferencia significativa para SLFT $(p=0.39)$ o SG $(p=0.61)$.
A cinco años, la SLFT fue del 93\% (IC 95\%: 90.594.8) con el uso de cuatro ciclos y del $91.1 \%$ con solo dos ciclos (IC 95\%: 88.3-93.2). Por el contrario, la toxicidad y eventos adversos fueron más comunes en quienes recibieron cuatro ciclos de QT y 30 Gy de $R T^{21}$.

\section{Tratamiento de rescate}

Hasta un $30 \%$ de los pacientes tratados inicialmente para LH presentarán recurrencia ${ }^{13,22}$. A estos pacientes se les administrará segunda línea y en caso de que haya respuesta a esta serán candidatos a TACPH como intento curativo. Las terapias de segunda línea pueden presentar RC en LH previo a Trasplante autologo de progenitores hematopoyeticos (TACPH) que oscila entre el 17 y el 76\% ${ }^{14,22}$. De hecho, la tasa de $\mathrm{RC}$ con los diferentes esquemas de segunda línea oscila entre el 20 y el $60 \%$. La profundidad de la respuesta es relevante, debido a que se ha demostrado que alcanzar una $\mathrm{RC}$ previo a trasplante es un predictor de pronóstico favorable. Otros esquemas utilizados 

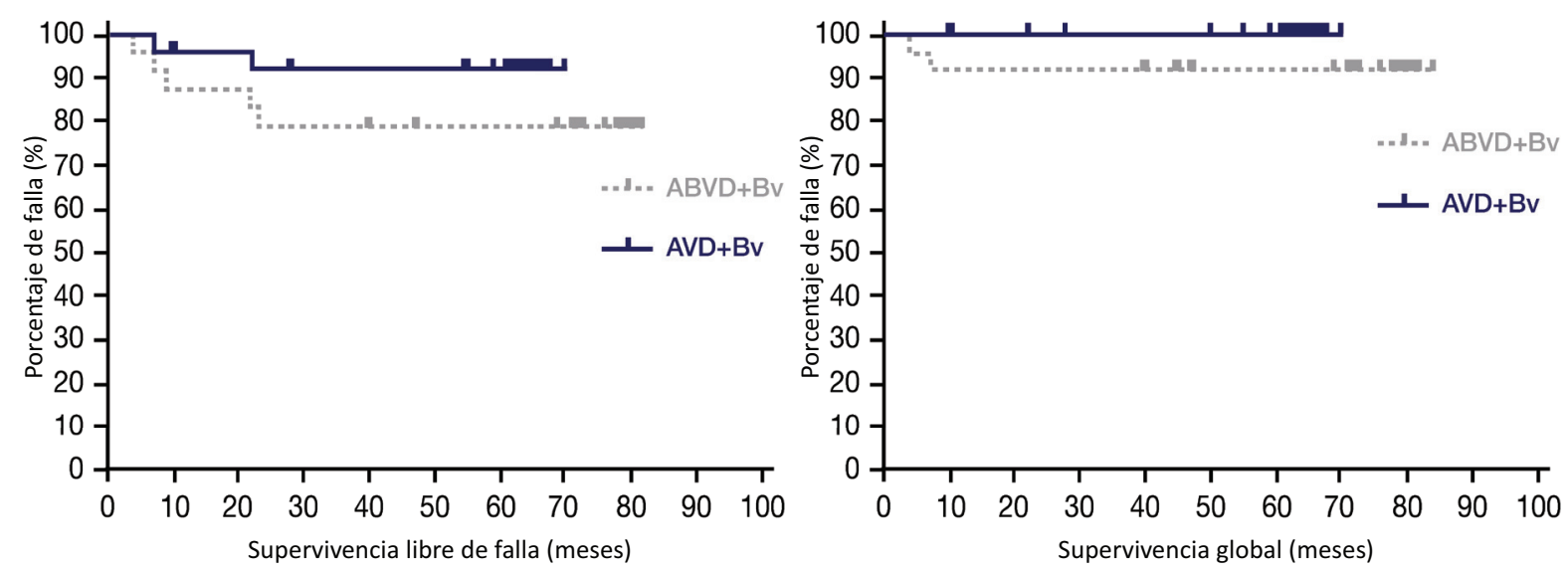

Figura 7. Esquema incorpora BV, $A+A V D$. En este estudio fase 3, el ensayo ECHELON-1, mostr. mejor SLP en A+AVD en comparación con ABVD en LHc estadios III y IV (tomada de Connors, et al., 2017'3).

$A B V D$ : doxorubicina (adriamicina), bleomicina, vinblastina y dacarbazina; BV: brentuximab vedotin; AVD: doxorubicina (adriamicina), vinblastina y dacarbazina.
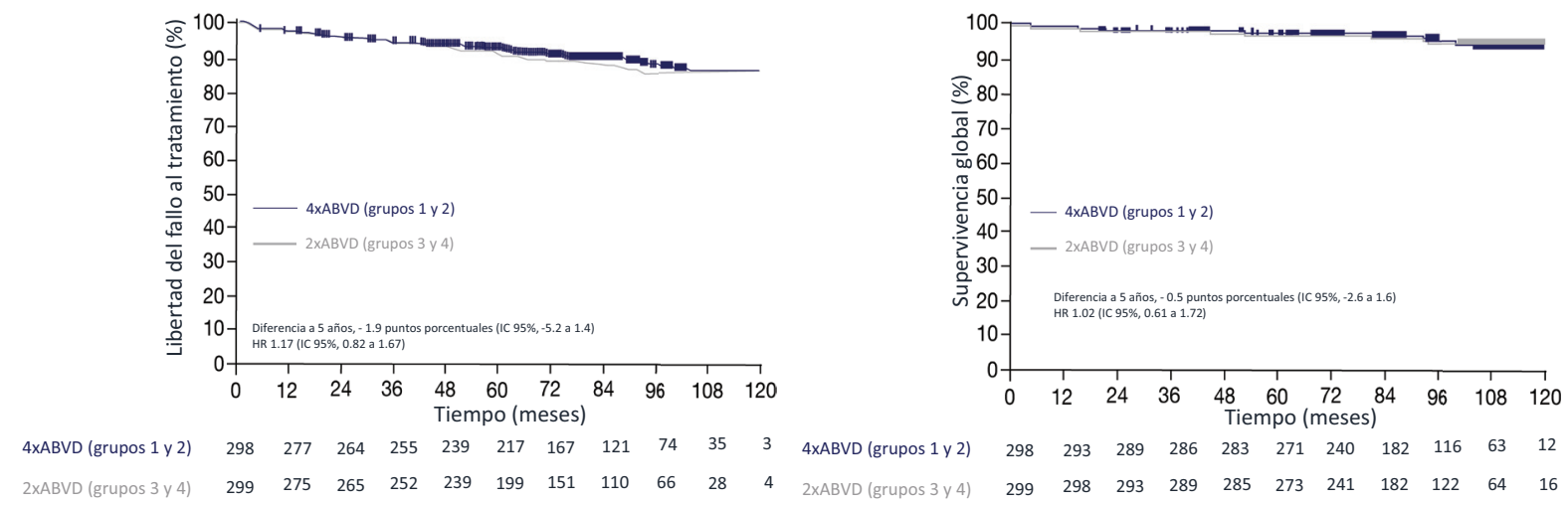

Figura 8. Comparación de grupos de diferentes dosis de quimioterapia (tomada de Engert, et al., 2010²1).

ABVD: doxorubicina (adriamicina), bleomicina, vinblastina y dacarbazina; IC 95\%: intervalo de confianza del 95\%.

han sido bendamustina + esquema basado en gemcitabina y vinorelbina (BEGEV). Este último esquema muestra una RG del $83 \%$ y una $\mathrm{RC}$ del $73 \%$, con una SLP a dos años del $62.2 \%$ en población en general y del $80.8 \%$ en pacientes trasplantados ${ }^{14,22}$.

\section{Tratamiento de enfermedad en recaída o refractaria}

Del 15 al 25\% de los pacientes con LHc fallarán al tratamiento de primera línea. Un 50\% de los pacientes podrán ser curados posterior a TACPH, aunque la mayoría con factores pronósticos desfavorables (p. ej., recaída en menos de 12 meses o refractariedad al tratamiento inicial, la mejor respuesta fue la parcial o $\mathrm{EE}$ a la última línea de tratamiento, enfermedad extranodal a la recaída previa a TACPH $0 \geq 2$ tratamientos de rescate previos) progresará posterior al trasplante con mal pronóstico. En estos pacientes con $\mathrm{R} / \mathrm{R}$ posterior a TACPH la mediana de SG es de 2.4 años y de 1.2 años si la recaída es en menos de 1 año del trasplante. Younes, et al. incluyeron 102 pacientes en un estudio fase II LH R/R posterior a TACPH a usar BV. Se administraron un máximo de 16 ciclos a dosis de $1.8 \mathrm{mg} / \mathrm{kg}$ cada tres semanas. La respuesta global objetiva fue del $75 \%$ con $\mathrm{RC}$ en el $34 \%$ de los pacientes. La mediana de SLP fue de 5.6 meses en pacientes con respuesta global objetiva y de 20.5 meses en $\mathrm{RC}^{15,22,23}$.

\section{Pronóstico a largo plazo}

En los pacientes de más de 60 años, el LH presenta peor evolución con regímenes habituales. La biología del LH difiere en pacientes mayores, siendo más 


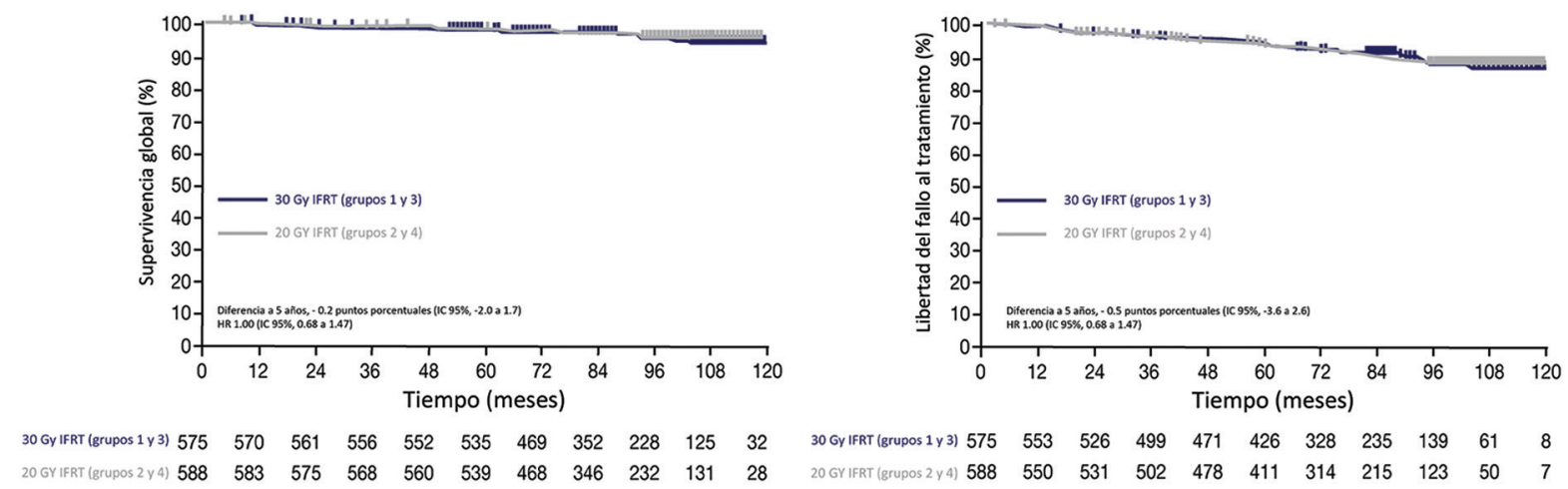

Figura 9. Comparación de grupos de diferentes dosis de radioterapia a campo involucrado (tomada de Engert, et al., 201021) IC 95\%: intervalo de confianza del 95\%; IFRT: radioterapia de campo de área involucrada.
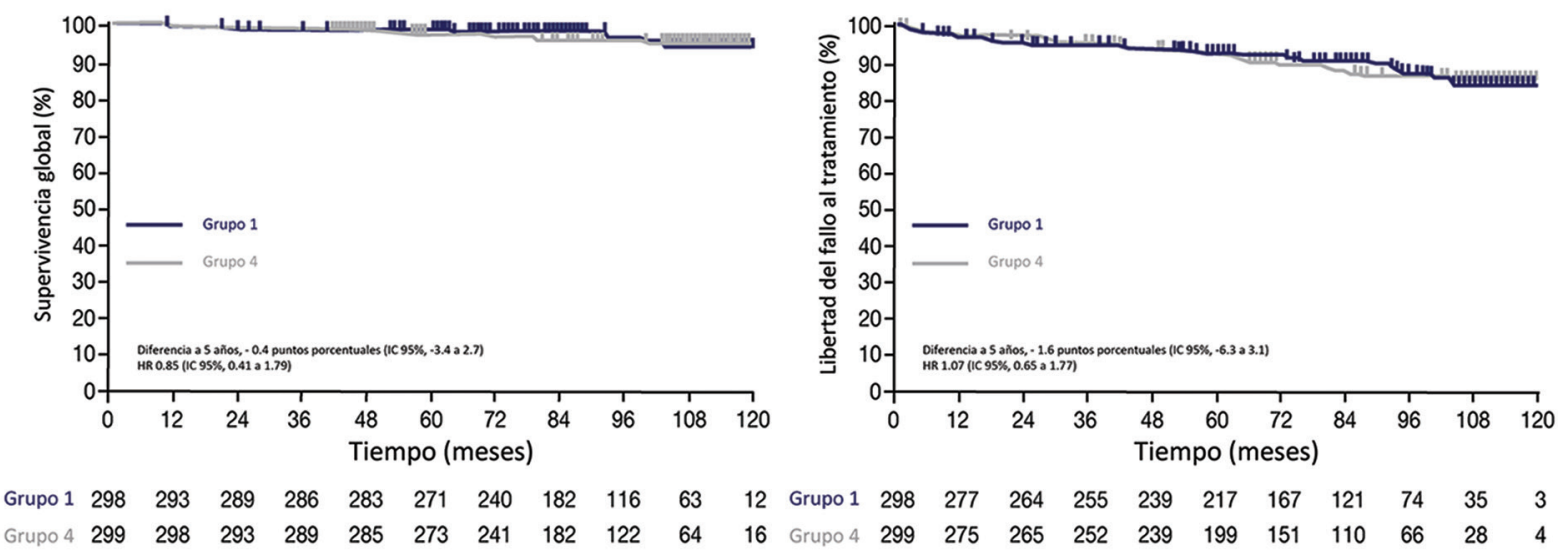

Figura 10. Comparación entre los grupos 1 y 4 (tomada de Engert, et al., 2010¹).

IC 95\%: intervalo de confianza del 95\%.

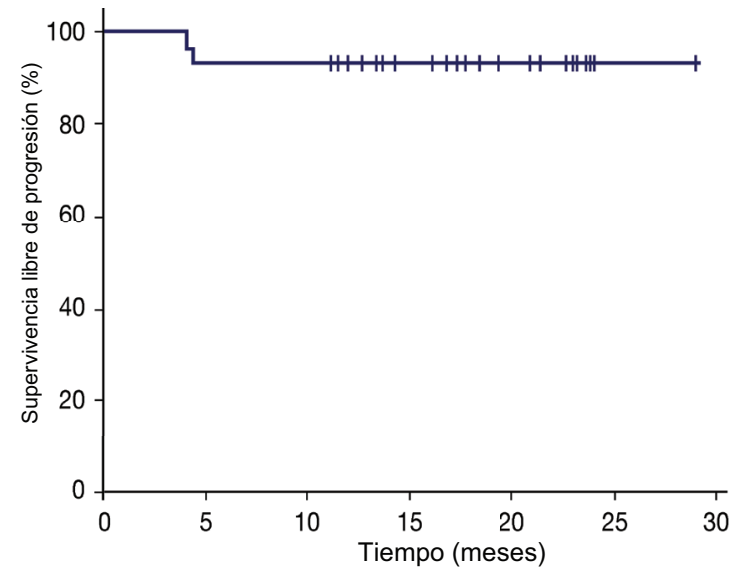

Figura 11. Supervivencia libre de progresión por intención de tratar a 18.8 meses (tomada de $\mathrm{Hu}$, et al., 201829).

frecuente en pacientes $>60$ años la variedad de Celularidad Mixta (CM), además de mayor positividad de VEB, con el consecuente mayor riesgo de desenlaces fatales ${ }^{19}$. Asimismo, la presencia de otras comorbilidades, principalmente la cardiaca, afectan el pronóstico del $\mathrm{LH}$ y el uso de regímenes habituales ${ }^{19}$. Los pacientes de este grupo etario presentan menos SLP (48 vs. $74 \%)$ y peor SG $(58 \text { vs. } 90 \%)^{22}$.

En mujeres tratadas con RT a nivel torácico por LH previamente existe un riesgo incrementado de cáncer mamario, el cual oscila de 5 a 20 veces más en comparación con la población general ${ }^{20}$. Seguimiento a 40 años, la incidencia acumulada de cáncer mamario en esta población es del 30-40\%. Esta elevada incidencia es similar a la de las portadoras de mutaciones BCRA1/223.

Se considera que el riesgo de cáncer mamario por RT en LH es modificado por dosis de RT y volumen radiado, la edad al momento de la exposición a RT, e inversamente proporcional al riesgo de cáncer, además de que también la menopausia prematura inducida por los agentes alquilantes del tratamiento del LH está presente ${ }^{22,23}$. 
Opstal, et al. analizaron 211,155 polimorfismos de un solo nucleótido de genes asociados con interacción con radiación o riesgo de cáncer mamario en 327 pacientes con cáncer mamario después de RT para LH y 4,671 pacientes con cáncer mamario primario. Las pacientes en el decil más alto del RT-interactionPRS (polygenic risk score) presentó un riesgo de 1.6 veces más alto que aquellos en el decil más bajo. Asimismo, en el breast cancer PRS el riesgo fue 4 veces mayor en los pacientes dentro del decil más alto en comparación al más bajo. Por lo tanto, la susceptibilidad a cáncer mamario en las supervivientes de LH estaría influenciada por factores genéticos inherentes a las pacientes ${ }^{23}$.

\section{Linfoma Hodgkin y VIH}

En pacientes con VIH habitualmente el LH tiene una presentación más ominosa, como estadios avanzados y compromiso extranodal (involucro de $\mathrm{MO}$ ), asociándose a VEB en el $80-100 \%$ de los $\operatorname{casos}^{21}$. El tipo histológico más frecuentemente es el de $\mathrm{CM}$. Por parte del enfermo, el conteo de linfocitos CD4+ al momento del diagnóstico de LH oscila habitualmente entre 150 y $260^{21}$. En pacientes en quienes se inicia manejo antirretroviral y los conteos de CD4 permanecen bajos, este es un factor de mal pronóstico ${ }^{24}$.

Por otro lado, la incidencia de LH en Pacientes VIH positivos se ha incrementado posterior a la introducción de la terapia antirretroviral de gran actividad (HAART). Las indicaciones de tratamiento y seguimiento son similares en $\mathrm{LH} / \mathrm{VIH}$ que en pacientes no infectados'. Asimismo, debe ser considerado TACPH en pacientes primariamente refractarios quimiosensibles al tratamiento de rescate 1 . Las tasas de $\mathrm{RC}$ son muy similares a la población general siendo del 74 al $87 \%$ y una SG a cinco años del $76-81 \%$. Los diferentes esquemas en primera línea son útiles también en $\mathrm{LH} / \mathrm{VIH}$, aunque el esquema BEACOPP reporta mayor toxicidad, con una mortalidad hasta del $7 \%$. Asimismo, en lo concerniente a LHNPL en pacientes con VIH el tratamiento es similar a la población general ${ }^{24}$.

Aproximadamente un 10 a $30 \%$ de los pacientes LHc/VIH presentará recaída posterior a RC. En estos casos, también está indicado segunda línea de QT y posterior TACPH, con buena evolución en el 30 al $65 \%$ de los casos 1 . En caso de recaída o refractariedad posterior a TACPH, se optará por rescate y trasplante alogénico con acondicionamiento reducido. A pesar de lo anterior, la mortalidad asociada a TAloPH en $\mathrm{LH} / \mathrm{VIH}$ es del $20 \%$, con supervivencia a dos años del $50 \%{ }^{23,24}$.

En lo concerniente al BV, Rubistein, et al. valoraron la seguridad del esquema BV+AVD en pacientes VIH con $\mathrm{LHC}^{22}$. Fueron excluidos aquellos pacientes que requerían antirretrovirales con fuerte inhibición de CYP3A4. Hubo negativización en $5 / 6$ pacientes en la PETi y en 6/6 la PET al finalizar el tratamiento. La SLP fue del $100 \%$ a 25 meses de seguimiento. Los niveles de linfocitos CD4+ y la carga viral no se vieron afectados durante el tratamiento, con incluso mejoría en $4 / 5$ pacientes posterior al segundo ciclo. En lo concerniente a efectos adversos, no hubo diferencia significativa con respecto a pacientes $\mathrm{VIH}$ negativos ${ }^{25}$. Wang, et al. han demostrado una negativización transitoria del ARN VIH-1 explicado de manera parcial en que existe una correlación lineal entre el incremento de los niveles de ARN VIH-1 plasmático y el estadio clínico con los niveles de CD30 soluble; reportándose que la señalización a través de CD30 incrementa la actividad transcripcional de $\mathrm{VIH}-1$. Por lo tanto, al ser inhibido CD30 existiría una disminución en la transcripción viral ${ }^{26}$.

Pese a las respuestas favorables al BV en pacientes $\mathrm{LH} / \mathrm{VIH}$, existe el riesgo teórico incrementado de leucoencefalopatía multifocal progresiva en esta población con el uso de BV. La presentación habitual de este efecto colateral es de semanas con respecto a la última exposición a BV. Teniendo en cuenta lo anterior, los criterios de elegibilidad en pacientes LH/ VIH para BV tal vez deberían ser:

- CD4 > 50 células $/ \mathrm{mL}$.

- Terapia HAART activa.

- RM de encéfalo previa a tratamiento.

- También se han obtenido resultados aceptables con los inhibidores del check point como nivolumab y pembrolizumab en esta población ${ }^{26,27}$.

\section{Nuevas líneas. Inmunoterapia}

La proteína de muerte celular programada 1 (PD-1) es un receptor importante de respuesta inmunitaria expresado en las células T. La PD-1 se une a su ligando (PD-L1 o PD-L2) en las células tumorales y en su microambiente promoviendo la tolerancia a la evasión tumoral, lo que facilita el crecimiento tumoral. Por lo anterior, esta proteína es importante en el sentido de que puede ser un blanco para restaurar la inmunidad antitumoral. En lo concerniente a LHc RR, la Food and Drug Administration ha aprobado el uso de nivolumab o pembrolizumab debido a sus elevadas 
tasas de respuesta. Su actividad se explica en el hecho de que las CRS sobreexpresan PD-L1/PD-L2, además de que silencian la expresión del complejo mayor de histocompatibilidad. En los pacientes con LHc, la PD-1 se encuentra en niveles mayores tanto en los linfocitos $T$ infiltrantes del linfoma como en sangre periférica, en comparación a personas sanas y en pacientes con linfoma no Hodgkin de células B. La mayoría de los pacientes con LHc presenta una amplificación del 9q24.1, lo que provoca una fuerte expresión de PD-L1/PD-L2. Las anormalidades del 9q24.1 más frecuentes son la ganancia en número de copias (58\%), amplificación (35\%) y polisomía (5\%), las cuales pueden ser detectadas en casi todos los pacientes con LHc por medio de hibridación fluorescente in situ. Los productos de codificación del VEB también pueden incrementar la expresión de PD-L1 en pacientes con aberraciones mutuamente excluyentes de $9 \mathrm{q} 24.1^{28}$.

En un grupo de 23 pacientes con Linfoma Hodgkin clásico recaida/refractarios. (LHc R/R), el nivolumab provocó una $R G$ del $87 \%$ y una RC del $17 \%$. El $35 \%$ de los pacientes presentó una duración de respuesta de hasta 1.5 años ${ }^{6,28,29}$.

Por otro lado, el pembrolizumab mostró una RG del $65 \%$ y una RC del 16\% en 31 pacientes con LHc RR, con una SLP de 11.4 meses $^{9,30}$.

En el estudio fase 2 CheckMate-205 se expusieron 243 pacientes con LHc RR que habían recaído posterior a TAutoPH a nivolumab. La RG fue del $69 \%$ y completa del 19\%, con una SLP de 12 a 18 meses. Se asoció la amplificación de PD-L1/PD-L2 a una alta tasa de respuesta al nivolumab y al pembrolizumab28,30.

En lo concerniente al pembrolizumab, el estudio fase 3 KEYNOTE-087 reportó en 210 pacientes LHc RR una RG del $69 \%$ y una RC del $22 \%{ }^{11,29}$.

Los efectos adversos de ambos agentes son diarrea, rash, prurito, reacción durante la infusión, astenia y distiroidismo, aunque solo un $4-6 \%$ de los pacientes han tenido que suspender el tratamiento ${ }^{30}$.

Por otro lado, el nivolumab puede presentar un fenómeno catalogado como pseudoprogresión, observado en el ensayo CheckMate-205, en donde 21 de los 70 pacientes que habían sido catalogados como con progresión de la enfermedad continuaron recibiendo nivolumab si existía beneficio clínico en pacientes sin rápido deterioro. La mayoría de este pequeño subgrupo presentó una reducción estable de la carga tumoral. Este incremento en el tamaño de las lesiones (pseudoprogresión) se explica por activación inmunitaria terapéutica o una respuesta inmunitaria tardía al tratamiento. Debido a lo anterior, esta pseudoprogresión se ha catalogado como respuesta indeterminada en las modificaciones recientes de la clasificación de Lugano en la era de inmunoterapia; recomendándose una reevaluación del caso en tres meses para confirmar o descartar una verdadera progresión. En pacientes con tratamiento posterior al trasplante alogénico, la RG fue del 95\% para nivolumab como monoterapia y RC del $42 \%$, con SLP a 1 año del $58 \%$ y del $79 \%$ en $S^{19,27,30}$.

En lo relativo al tratamiento de primera línea, se encuentran corriendo estudios de nivolumab en combinación con AVD (NCT03004833), AVD+B (bleomicina) (NCT03033914) o A (brentuximab) + AVD (NCT03233347). El pembrolizumab también se está investigando combinado con AVD como primera línea en LHc (NCT03226249). Asimismo, se ha explorado la combinación de pembrolizumab con vinblastina o brentuximab en pacientes de edad avanzada ${ }^{29,30}$.

La combinación de nivolumab y brentuximab como primera línea presenta una $R G$ del $82 \%$ y una $R C$ del $61 \%$. No obstante las respuestas favorables, un $44 \%$ de los pacientes experimentó reacciones de infusión grado $1 / 2$ y un $84 \%$ de los pacientes eventos adversos de tipo inmunitario, aunque solo el $8 \%$ requirió el uso de esteroides sistémicos ${ }^{29}$.

Por último, la inmunoterapia dual por combinación de bloqueo PD-1 y CTLA-4 también se ha estudiado en LHc RR con un $29 \%$ de pacientes con efectos adversos grado 3 , debiendo descontinuar el tratamiento un $8 \%{ }^{28,29}$.

La SLP a cinco años en pacientes con estadios tempranos de LHc clasificados como riesgo desfavorable es del 80 al $85 \%$. Fue un estudio multicéntrico evaluando la seguridad y eficacia de BV y AVD, con RT como consolidación ( $30 \mathrm{~Gy}$ ) a campo involucrado. Se trató a los pacientes con cuatro ciclos de A+AVD. Los pacientes que alcanzaran RC por PET (Deauville 1-3) recibirían la RT a dosis mencionada. Tres o más eventos adversos se observaron en cuatro pacientes (neutropenia grave febril, neuropatía periférica e hipertensión). Se alcanzó PET negativa en el 93\% de los pacientes tras cuatro ciclos. Los 27 pacientes que se sometieron a los cuatro ciclos A+AVD y RT presentaron RC, con una SLP a un año del $93.3 \%$. Se concluye por los autores una buena respuesta incluso en pacientes con alta carga tumoral. Los efectos adversos reportados fueron la neutropenia grave febril en el $53 \%$ de los pacientes y neuropatía periférica en el $40 \%$. Ningún paciente presentó toxicidad pulmonar significativa (grado 2 o mayor) (Fig. 11) ${ }^{30,31}$. 
Se valoró la respuesta a retratamiento con BV en pacientes con LHc quienes previamente se habían expuesto al fármaco en cuestión y hubiesen presentado una respuesta mínima parcial. La RG fue del $60 \%$, con un $30 \%$ alcanzando RC y una duración de esta de 9.5 meses. Los EA tuvieron la misma incidencia, a excepción de la neuropatía periférica, la cual mostró un efecto acumulativo ${ }^{30,31}$.

Chen, et al. realizaron un estudio multicéntrico fase Il en el cual examinaron la tolerabilidad y actividad de BV en LH RR posterior a primera línea. En 37 pacientes, la RG fue del $68 \%$, con un $35 \%$ de RC. Los pacientes que no alcanzaron $\mathrm{RC}$ previo a trasplante se sometieron a tratamiento citotóxico (p. ej., ICE) con un adicional $35 \%$ logrando RC (total $65 \%$ ). El $86 \%$ del total de la muestra fue elegible para trasplante. Debido a que la tasa de RC al término de dos ciclos de BV es casi nula los autores recomiendan tratamiento citotoxico en todos los pacientes. En este trabajo, la expresión de CD68 no afectó las respuestas al BV. Asimismo, el BV no afectó en el éxito de la cosecha de Trasplante autologo de progenitores hematopoyeticos (TACPH).

Los autores indagaron acerca de las preferencias de los pacientes y médicos tratantes sobre los distintos esquemas en LH. Los esquemas evaluados fueron ABVD, BEACOPP y BV+AVD. En los tres países en los que se llevó a cabo la encuesta (Reino Unido, Francia y Alemania) la posibilidad de toxicidad pulmonar afectó de manera importante la decisión del esquema a utilizar. Se evidenció que los médicos prefieren una mejor SG sobre SLP, mientras que ocurre lo opuesto en los pacientes. Por lo que los pacientes usualmente preferirían un tratamiento más tóxico, aunque con mayores posibilidades de éxito ${ }^{32}$.

\section{Conflicto de intereses}

Dr. José Luis Alvarez Vera, Conferencista para Novartis, Roche, Janssen, Bristol y Takeda.

\section{Financiamiento}

La realización de este trabajo de consenso fue auspiciada por un donativo no restringido al grupo de trabajo por Takeda, México. Las sugerencias presentadas en el siguiente documento son opinión de los autores y no representan una opinión o recomendación oficial de alguna sociedad o compañía editorial.

\section{Responsabilidades éticas}

Protección de personas y animales. Los autores declaran que para esta investigación no se han realizado experimentos en seres humanos ni en animales.

Confidencialidad de los datos. Los autores declaran que en este artículo no aparecen datos de pacientes.

Derecho a la privacidad y consentimiento informado. Los autores declaran que en este artículo no aparecen datos de pacientes.

\section{Bibliografía}

1. Küppers R, Rajewsky K. The origin of Hodgkin and Reed/Sternberg Cells in Hodgkin's Disease. Annu Rev Immunol. 1998;16:471-93.

2. Küppers R. The biology of Hodgkin's lymphoma. Nat Rev Canc. 2009:9(1):15-27.

3. Ansell SM. Hodgkin lymphoma: Diagnosis and treatment. Mayo Clin Proc. 2015;90(11):1574-83

4. Eichenauer DA, Aleman BMP, André M, Federico M, Hutchings M, Illidge T, et al. Hodgkin lymphoma: ESMO Clinical Practice Guidelines for diagnosis, treatment and follow-up. Ann Oncol. 2018; 29(Suppl 4):iv19-iv29.

5. Lister TA, Crowther D, Sutcliffe SB, Glatstein E, Canellos GP, Young RC, et al. Report of a committee convened to discuss the evaluation and staging of patients with Hodgkin's disease: Cotswolds meeting. J Clin Oncol. 1989;7(11):1630-6.

6. Swerdlow SH, Campo E, Pileri SA, Harris NL, Stein H, Siebert R, et al. The 2016 revision of the World Health Organization classification of lymphoid neoplasms. Blood. 2016;127(20):2375-90.

7. Barrington SF, Kirkwood AA, Franceschetto A, Fulham MJ, Roberts TH, Almquist $\mathrm{H}$, et al. PET-CT for staging and early response: results from the Response-Adapted Therapy in Advanced Hodgkin Lymphoma study. Blood. 2016;127(12):1531-8.

8. Barrington SF, Mikhaeel NG, Kostakoglu L, Meignan M, Hutchings M, Müeller SP, et al. Role of imaging in the staging and response assessment of Iymphoma: Consensus of the International Conference on Malignant Lymphomas Imaging Working Group. J Clin Oncol. 2014;32(27):3048-58.

9. Advani RH, Hoppe RT, Baer D, Mason J, Warnke R, Allen J, et al. Efficacy of abbreviated Stanford V chemotherapy and involved-field radiotherapy in early-stage Hodgkin lymphoma: mature results of the G4 trial. Ann Oncol. 2013;24(4):1044-8.

10. Gordon LI, Hong F, Fisher RI, Bartlett NL, Connors JM, Gascoyne RD, et al. Randomized phase III trial of ABVD versus Stanford V with or without radiation therapy in locally extensive and advanced-stage Hodgkin lymphoma: An intergroup study coordinated by the Eastern Cooperative Oncology Group (E2496). J Clin Oncol. 2013;31(6):684-91.

11. Cheson BD, Fisher RI, Barrington SF, Cavalli F, Schwartz LH, Zucca E, et al. Recommendations for initial evaluation, staging, and response assessment of Hodgkin and non-Hodgkin lymphoma: the Lugano classification. J Clin Oncol. 2014;32(27):3059-68.

12. O'Connor OA, Lue JK, Sawas A, Amengual JE, Deng C, Kalac M, et al. Brentuximab vedotin plus bendamustine in relapsed or refractory Hodgkin's lymphoma: an international, multicentre, single-arm, phase 1-2 trial. Lancet Oncol. 2018;19(2):257-66.

13. Connors JM, Ansell SM, Fanale M, Park SI, Younes A. Five-year follow-up of brentuximab vedotin combined with ABVD or AVD for advanced-stage classical Hodgkin lymphoma. Blood. 2017;130(11):1375-7.

14. LaCasce AS, Bociek RG, Sawas A, Caimi P, Agura E, Matous J, et al. Brentuximab vedotin plus bendamustine: a highly active first salvage regimen for relapsed or refractory Hodgkin lymphoma. Blood. 2018;132(1):40-8.

15. Moskowitz CH, Walewski J, Nademanee A, Masszi T, Agura E, Holowiec$\mathrm{ki} \mathrm{J}$, et al. Five-year PFS from the AETHERA trial of brentuximab vedotin for Hodgkin lymphoma at high risk of progression or relapse. Blood. 2018:132(25):2639-42.

16. Herrera AF, Palmer J, Martin P, Armenian S, Tsai NC, Kennedy N, et al. Autologous stem-cell transplantation after second-line brentuximab vedotin in relapsed or refractory Hodgkin lymphoma. Ann Oncol. 2018;29(3):724-30.

17. Vitolo U, Chiappella A. Salvage regimens for Hodgkin's lymphoma in the brentuximab vedotin era. Lancet Oncol. 2018;19(2):162-3. 
18. Younes A, Gopal AK, Smith SE, Ansell SM, Rosenblatt JD, Savage KJ, et al. Results of a pivotal phase II study of brentuximab vedotin for patients with relapsed or refractory Hodgkin's lymphoma. J Clin Oncol. 2012;30(18):2183-9.

19. Moskowitz AJ, Schöder H, Yahalom J, McCall SJ, Fox SY, Gerecitano J, et al. PET-adapted sequential salvage therapy with brentuximab vedotin followed by augmented ifosamide, carboplatin, and etoposide for patients with relapsed and refractory Hodgkin's lymphoma: a non-randomised, open-label, single-centre, phase 2 study. Lancet Oncol. 2015; 16(3):284-92

20. Younes A, Connors JM, Park SI, Fanale M, O'Meara MM, Hunder NN et al. Brentuximab vedotin combined with ABVD or AVD for patients with newly diagnosed Hodgkin's lymphoma: a phase 1, open-label, dose-escalation study. Lancet Oncol. 2013;14(13):1348-56.

21. Engert A, Plütschow A, Eich HT, Lohri A, Dörken B, Borchmann $\mathrm{P}$, et al. Reduced treatment intensity in patients with early-stage Hodgkin's lymphoma. N Engl J Med. 2010;363(7):640-52.

22. Forero-Torres A, Holkova B, Goldschmidt J, Chen R, Olsen G, Boccia RV et al. Phase 2 study of frontline brentuximab vedotin monotherapy in Hodgkin lymphoma patients aged 60 years and older. Blood. 2015 126(26):2798-804

23. Opstal-van Winden AWJ, de Haan HG, Hauptmann M, Schmidt MK Broeks A, Russell NS, et al. Genetic susceptibility to radiation-induced breast cancer after Hodgkin lymphoma. Blood. 2019;133(10):1130-9.

24. Re A, Cattaneo C, Rossi G. HIV and lymphoma from epidemiology to clinical management. Mediterr J Hematol Infect Dis. 2019;11(1).
25. Rubinstein PG, Moore PC, Rudek MA, Henry DH, Ramos JC, Ratner L, et al. Brentuximab vedotin with AVD shows safety, in the absence of strong CYP3A4 inhibitors, in newly diagnosed HIV-associated Hodgkin lymphoma. AIDS. 2018;32(5):605-11.

26. Wang CC, Thanh C, Gibson EA, Ball-Burack M, Hogan LE, Descours B et al. Transient loss of detectable HIV-1 RNA following brentuximab vedotin anti-CD30 therapy for Hodgkin lymphoma. Blood Adv. 2018; 2(23):3479-82.

27. Gandhi $M$, Petrich $A$. Brentuximab vedotin in patients with relapsed HIV-related lymphoma. J Natl Compr Canc Netw. 2014;12(1):16-9.

28. Ramchandren $\mathrm{R}$, Advani $\mathrm{RH}$, Ansell SM, et al. Brentuximab vedotin plus chemotherapy in North American subjects with newly diagnosed stage III or IV Hodgkin lymphoma. Clin Cancer Res. 2019;25(6):1718-26.

29. Hu B, Jacobs R, Ghosh N. Checkpoint Inhibitors Hodgkin lymphoma and non-Hodgkin lymphoma. Curr Hematol Malig Rep. 2018;13(6):543-54.

30. Kumar A, Casulo C, Yahalom J, Schöder H, Barr PM, Caron P, et al Brentuximab vedotin and AVD followed by involved-site radiotherapy in early stage, unfavorable risk Hodgkin lymphoma. Blood. 2016; 128(11):1458-64.

31. Bartlett NL, Chen R, Fanale MA, Brice P, Gopal A, Smith SE, et al. Retreatment with brentuximab vedotin in patients with CD30-positive hematologic malignancies. J Hematol Oncol. 2014;7(1):24.

32. Chen R, Palmer JM, Martin P, Tsai N, Kim Y, Chen BT, et al. Results of a multicenter phase II trial of brentuximab vedotin as second-line therapy before autologous transplantation in relapsed/refractory Hodgkin lymphoma. Biol Blood Marrow Transplant. 2015;21(12):2136-40. 